\title{
Risk Factors for Contra-Lateral Secondary Anterior Cruciate Ligament Injury: A Systematic Review with Meta-Analysis
}

\author{
Anna Cronström ${ }^{1,2}$ (]) Eva Tengman ${ }^{1} \cdot$ Charlotte K. Häger $^{1}$
}

Accepted: 27 December 2020 / Published online: 30 January 2021

(c) The Author(s) 2021

\begin{abstract}
Background The risk of sustaining a contra-lateral anterior cruciate ligament (C-ACL) injury after primary unilateral ACL injury is high. C-ACL injury often contributes to a further decline in function and quality of life, including failure to return to sport. There is, however, very limited knowledge about which risk factors that contribute to C-ACL injury.

Objective To systematically review instrinsic risk factors for sustaining a C-ACL injury.

Methods A systematic review with meta-analysis was performed according to the Preferred Reporting Items for Systematic Reviews and Meta-Analyses guidelines. Four databases (MEDLINE, CINAHL, EMBASE, Sport Discus) were searched from inception to January 2020. Inclusion criteria were prospective or retrospective studies investigating any intrinsic risk factor for future C-ACL injury. Meta-analysis was performed and expressed as odds ratios (OR) if two or more articles assessed the same risk factor.

Results 44 moderate-to-high quality studies were eventually included in this review, whereof 35 studies were eligible for meta-analysis, including up to 59000 individuals. We identified seven factors independently increasing the odds of sustaining a C-ACL injury (in order of highest to lowest OR): (1) returning to a high activity level (OR 3.26, 95\% CI 2.10-5.06); (2) Body Mass Index < 25 (OR 2.73, 95\% CI 1.73-4.36); (3) age $\leq 18$ years (OR 2.42, 95\% CI 1.51-3.88); (4) family history of ACL injury (OR 2.07, 95\% CI 1.54-2.80); (5) primary ACL reconstruction performed $\leq 3$ months post injury (OR 1.65, 95\% CI: 1.32-2.06); (6) female sex (OR 1.35, 95\% CI 1.14-1.61); and (7) concomitant meniscal injury (OR 1.21, 95\% CI 1.03-1.42). The following two factors were associated with decreased odds of a subsequent C-ACL injury: 1) decreased intercondylar notch width/width of the distal femur ratio (OR 0.43, 95\% CI 0.25-0.69) and 2) concomitant cartilage injury (OR 0.83, 95\% CI 0.69-1.00). There were no associations between the odds of sustaining a C-ACL injury and smoking status, pre-injury activity level, playing soccer compared to other sports or timing of return to sport. No studies of neuromuscular function in relation to risk of C-ACL injury were eligible for meta-analysis according to our criteria.

Conclusion This review provides evidence that demographic factors such as female sex, young age ( $\leq 18$ years) and family history of ACL injury, as well as early reconstruction and returning to a high activity level increase the risk of C-ACL injury. Given the lack of studies related to neuromuscular factors that may be modifiable by training, future studies are warranted that investigate the possible role of factors such as dynamic knee stability and alignment, muscle activation and/or strength and proprioception as well as sport-specific training prior to return-to-sport for C-ACL injuries.
\end{abstract}

PROSPERO: CRD42020140129.

Supplementary Information The online version contains supplementary material available at https://doi.org/10.1007/s4027 9-020-01424-3.

Anna Cronström

anna.cronstrom@umu.se

1 Department of Community Medicine and Rehabilitation, Umeå University, Umeå, Sweden

2 Department of Health Sciences, Lund University, Lund, Sweden

\section{Background}

Anterior cruciate ligament (ACL) injury is a common sports-related injury $[1,2]$ which often results in functional limitations and a lower activity level that may persist over time [3-6].

Indeed, many ACL-injured individuals never return to their pre-injury activity level [7]. Additionally, the risk of sustaining a subsequent contra-lateral ACL (C-ACL) injury is high and has even been reported to be significantly higher 


\section{Key Points}

Returning to a high activity level was the risk factor with the highest odds for sustaining a contra-lateral anterior cruciate ligament (C-ACL) injury following primary unilateral ACL injury.

In addition, females, individuals younger than 18 years, those with a family history of ACL injury and those receiving primary reconstruction within 3 months of injury had an increased risk of C-ACL.

Very few studies were identified investigating the poten tial influence of modifiable factors, including muscle strength, movement patterns and knee stability on the risk of C-ACL injury.

than suffering a new injury to the ipsi-lateral knee [8, 9]. A systematic review with meta-analysis from 2016 calculated the overall C-ACL injury rate to be around $8 \%$, and even higher $(12 \%)$ in younger individuals involved in sports at an elite level [9]. Sustaining a C-ACL injury is associated with even further decline in function and quality of life, lower level of activity and increased risk of failure to return to sport/activity compared to unilateral injury [10]. Nevertheless, little attention has been given to the matter in research and the different factors that may pre-dispose some individuals for subsequent ACL injuries remain unclear [11].

Previous research has established several risk factors for primary ACL injury, such as female sex [1], increased joint laxity [12], BMI [13, 14], family history [15], reduced lower extremity strength [16] and altered trunk and knee biomechanics [16]. However, given that individuals with ACL injury exhibit altered sensorimotor function, such as reduced lower extremity strength [17], altered biomechanics [18] and impaired neuromuscular control [17] compared to non-injured individuals, the risk factors for C-ACL injury may be entirely different from those associated with primary injury. Currently, there is some evidence identifying younger age and higher activity level as risk factors for subsequent ACL injury to either knee [9], whereas conflicting results have been reported for sex, family history and geometrics as risk factors for C-ACL injury [11]. To our knowledge, all potential instrinsic (patient-related) risk factors for C-ACL injury have never been systematically synthezised. To identify the factors that pre-dispose individuals to $\mathrm{C}$-ACL injury after primary ACL injury is important for screening of injury risk as well as for optimizing training and rehabilitation after ACL injury to minimize the risk of re-injury and associated consequences for these individuals. Thus, the aim of this study was to systematically review instinsic risk factors related to demographics, biomechanics, geometrics and function, that could each be independently associated with sustaining a C-ACL injury.

\section{Methods}

This systematic review with meta-analysis was conducted according to the Preferred Reporting Items for Systematic Reviews and Meta-Analyses (PRISMA) guidelines [19, 20]. The study protocol was pre-registered (PROSPERO: CRD42020140129; n.b. registration and search terms reflect a larger review initially also including graft rupture).

\subsection{Literature Search and Study Selection}

A systematic search in MEDLINE (PubMed), CINAHL, EMBASE and Sport Discus was performed from inception to June 2019 and updated in January 2020 using the following terms:

\subsubsection{Search Strategy}

(anterior cruciate ligament [MeSH Terms] OR anterior cruciate ligament reconstruction [MeSH Terms] OR anterior cruciate ligament injury [MeSH Terms] OR "lower extremity" [Title/Abstract] OR "ACL injur*" [Title/Abstract] OR "anterior cruciate ligament injur*" [Title/Abstract] OR construct* [Title/Abstract]) AND ("risk factor*" [Title/ Abstract] OR “injury risk" [Title/Abstract] OR "associated with" [Title/Abstract] OR predict* [Title/Abstract] OR relat* AND ("graft injur*" [Title/Abstract] OR "second* injur*" [Title/Abstract] OR reinjur*[Title/Abstract] OR re-injur* [Title/Abstract] OR rupture* [Title/Abstract] OR "graft failure*" [Title/Abstract]) OR "contralateral injur*" [Title/Abstract] OR "contra-lateral injur*" [Title/Abstract]).

In CINAHL, EMBASE and Sport Discus the search was performed without MeSH-terms. In addition, reference lists of all relevant articles were hand-searched for additional studies. The search was not restricted to any publication date.

\subsubsection{Eligibility Criteria}

Criteria for studies to be included were: (1) prospective or retrospective studies with a follow-up of any duration; (2) inclusion of males and/or females of any age with ACL injury treated with or without reconstruction; (3) assessment of any intrinsic factor (e.g. demographics, geometrics, function) at baseline; and (4) recording of at least $3 \mathrm{C}-\mathrm{ACL}$ injuries during the study period. Exclusion critera were: (1) animal studies and in vitro studies; (2) case studies, conference abstracts, review papers and editorials; (3) external risk factors (e.g. playing surface) or possible risk factors related 
to type of graft and/or surgery technique; or (4) published in a language other than English or Scandinavian language.

\subsection{Data Extraction and Synthesis}

Two researchers (AC and ET) independently screened the titles, abstracts and full papers according to the inclusion/ exclusion criteria. Any disagreements were resolved by a consensus discussion between $\mathrm{AC}$ and $\mathrm{EA}$, and if required with a third researcher $(\mathrm{CH})$. The following data were extracted from the studies: authors, publication date, number of participants, sex, age, activity level, proportion of participants sustaining a C-ACL injury, follow-up period (years), assessed risk factor (i.e. demographic, biomechanical, functional) and effect size (odds ratio). If data were not sufficiently reported in the studies, study authors were contacted and additional information was requested. A metaanalysis was performed if there were two or more studies that included the same factor, e.g. age or sex as a possible risk factor for C-ACL injury as well as metrics possible to calculate to odds ratio.

Comprehensive Meta-Analysis software, version 2.2.064 (Englewood, USA) was used for meta-analyses. The effect size was calculated as the odds ratio (95\% CI) for each risk factor for sustaining a C-ACL injury. If an odds ratio was not provided in the studies, the odds ratio was calculated from the number of events and sample size. A random effect model was used due to expected heterogeneity between studies, such as sex, age, follow-up duration and activity level. Between-studies effect size heterogeneity was calculated with the $Q$-test and expressed as $I^{2}$-statistics. A $p$ value equal to or less than 0.05 was considered statistically significant. For studies reporting associated meniscal injuries and different types of meniscal surgeries as risk factors for C-ACL, the results for any meniscal injury (medial or lateral injury) and "any meniscal surgery" (different types of surgery pooled) were included in the meta-analysis. If medial and lateral injury was only reported separately, the result for the side (medial/lateral) included in most studies were included in the analysis and if equal, the medial side was chosen due to being the side most frequently injured [21]. Subgroup analysis for pediatrics, defiend as age $<19$ years, were performed if more than one study investigated the same factor for that particular subgroup. Furthermore, sensitivity analyses for different aspects of the studies, e.g., participants' age and follow-up duration, were performed if there were $\geq 3$ studies that assessed the same risk factor.

\subsection{Quality Assessment and Publication Bias}

An adapted version $[22,23]$ of the checklist by Downs and Black [24] (online resource 1) was used for assessment of methodological quality of the included studies by two independent reviewers (AC and ET). Any disagreements were resolved by a consensus discussion between these two reviewers and if not resolved, with a third researcher $(\mathrm{CH})$. Publication bias was explored using funnel plots with trim and fill [25] if the analysis included at least ten studies [26].

\section{Results}

A total of 2784 abstracts were screened according to the inclusion/exclusion criteria and 263 full-text articles were subsequently screened. 202 of those were excluded due to failure to meet the inclusion criteria. 15 articles [27-41] pooled graft rupture and C-ACL injury as second injuries or stratified their result according to different graft types instead of C-ACL injury/no C-ACL injury. The authors of these articles were contacted and additional data specifically related to C-ACL injury were requested and subsequently provided for four studies [28, 32, 34, 36]. Of these four, one study [28] was the only report assessing the included risk factors of kinematics and kinetics, and therefore, although data were made available, it was not possible to include these data in any meta-analysis. Consequently, this study was not part of further analysis or descriptive results. Three articles [42-44] reported partly on the same individuals. Of these, we included the article that provided most data on risk factors and sufficient statistics [42]. Data from three other articles [45-47] were also included in previously published studies [48-50]. Of those, the articles with the greatest sample sizes [45, 47, 49] were included. Consequently, 44 articles were included in this review $[8,10,32,34,36$, $42,45,47,49,51-85]$ and were assessed for methodological quality (Fig. 1).

\subsection{Study Characteristics}

Of the 44 included studies, nine $[53,57,59,61,67,68,70$, $85]$ were excluded from the meta-analysis due to being the only study reporting on a specific factor or using specific statistics that were not possible to calculate to odds ratios. The caracteristics and results of these studies are reported in online resource 2 . Hence, 35 studies in total (16 retrospective and 19 prospective), with a follow-up period of 6 months to 20 years, were included in the meta-analysis. Of these, 28 studies reported on sex difference, 15 studies on age at primary injury, three studies on Body Mass Index (BMI), three studies on smoking status, nine studies on family history (defined as any sibling or parent with a history of ACL injury), seven studies on associated injuries, two studies on geometrics, eight studies on type of sport or return to sport and two studies on timing of primary reconstruction as a risk factor for C-ACL injury. No studies on neuromuscular function, such as muscle strength, muscle activation 


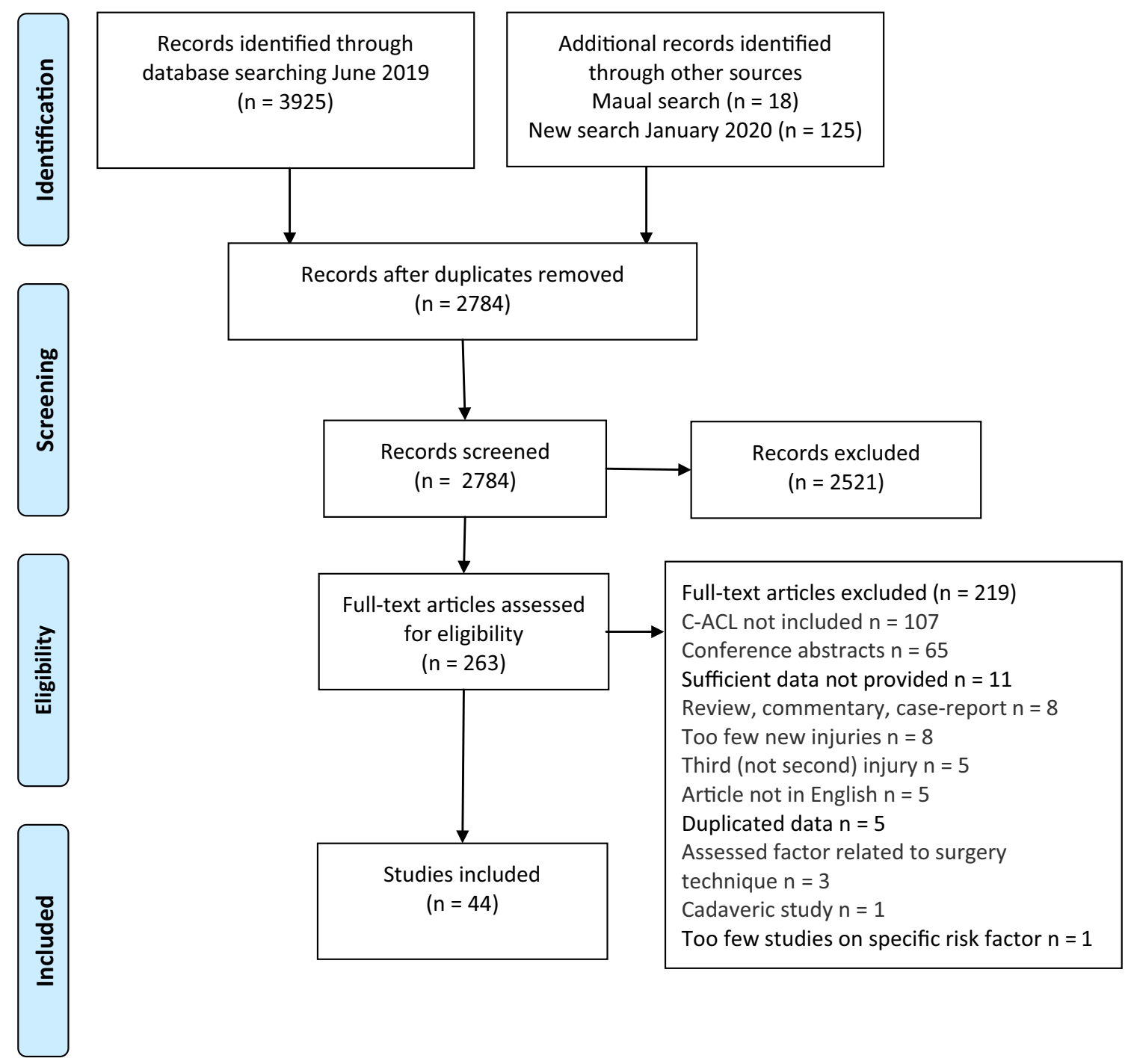

Fig. 1 Flow chart of the inclusion process

or movement pattern were eligible for meta-analysis according to our criteria. One study included only females [51], information on sex was not available in two studies [77, 81], whereas the remaining studies included both sexes. Twentynine studies pooled children and adults, two studies included only adults $[10,32]$, one study reported separate results for adults and children [75], whereas four studies included only children and adolescents $[55,65,69,78]$ (see Table 1 for characteristics of the individual studies included in the metaanalyses). In addition, fourteen of these included studies also involved potential risk factors (e.g. self-reported function, knee laxity, knee muscle strength and Tanner stage) not eligible for meta-analysis (only study reporting on a specific factor or using specific statistics that were not possible to calculate to odds ratios). These are likewise reported in online resource 2 .

\subsection{Synthesis of Results}

Meta-analyses consisting of between 2 and 28 studies, were performed separately for each C-ACL risk factor. The number of included studies for each meta-analysis is presented below.

\subsubsection{Sex}

Based on 28 studies, females had increased odds of sustaining a C-ACL injury compared to males (OR 1.35, 95\% CI 1.14-1.61, $p<0.001$, C-ACL injury $n=2259$, controls $n=57189$ (Fig. 2). 


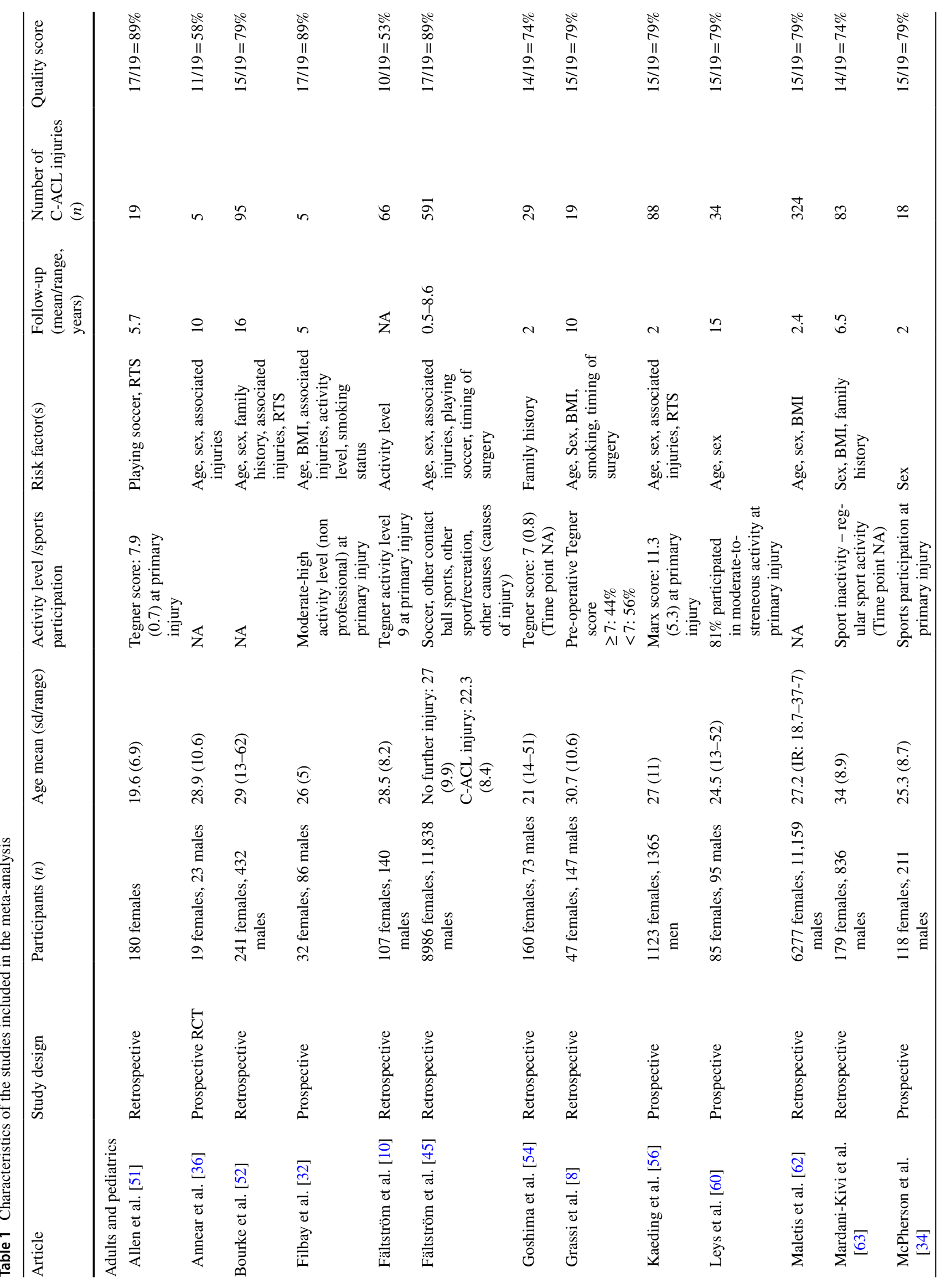




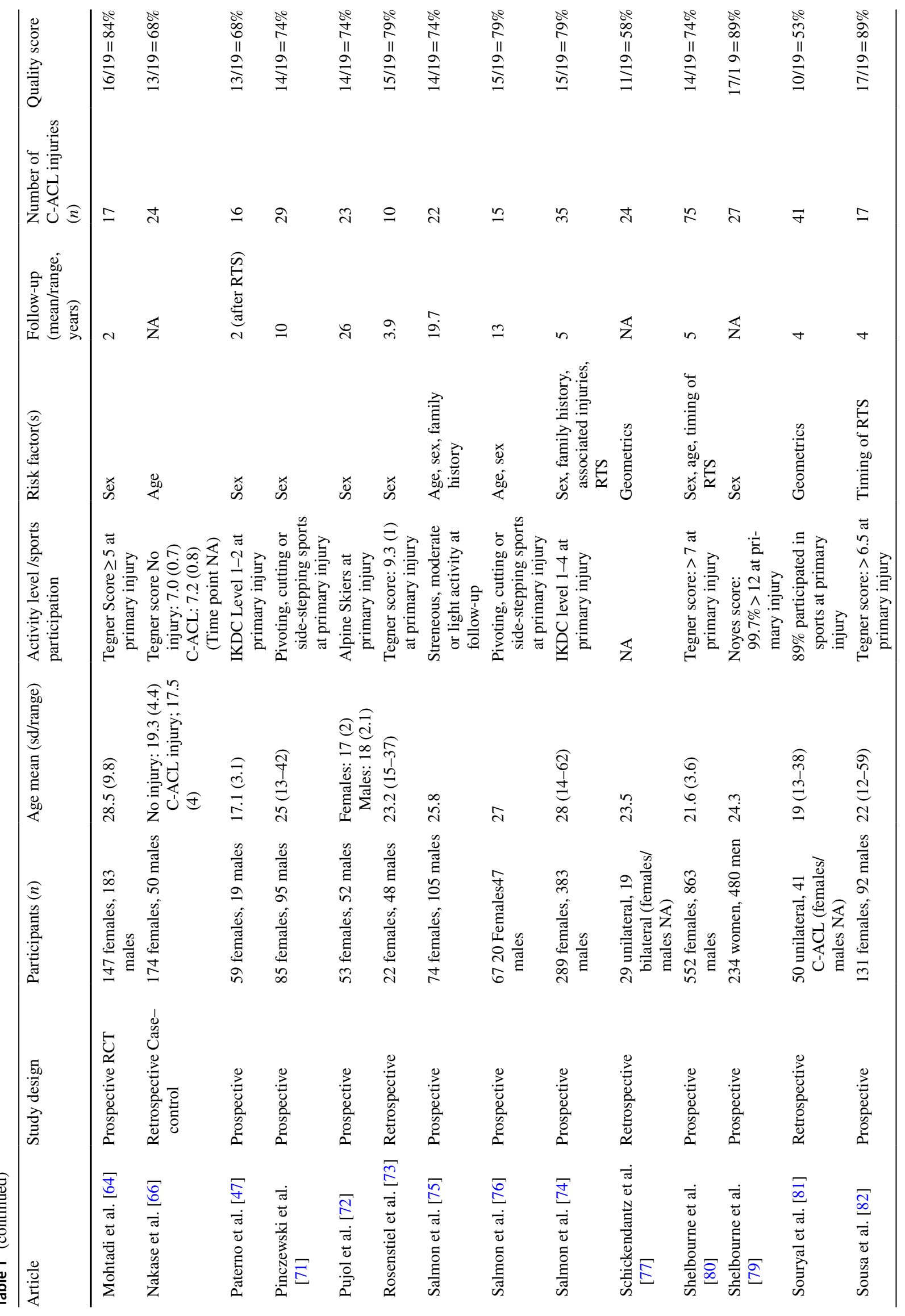




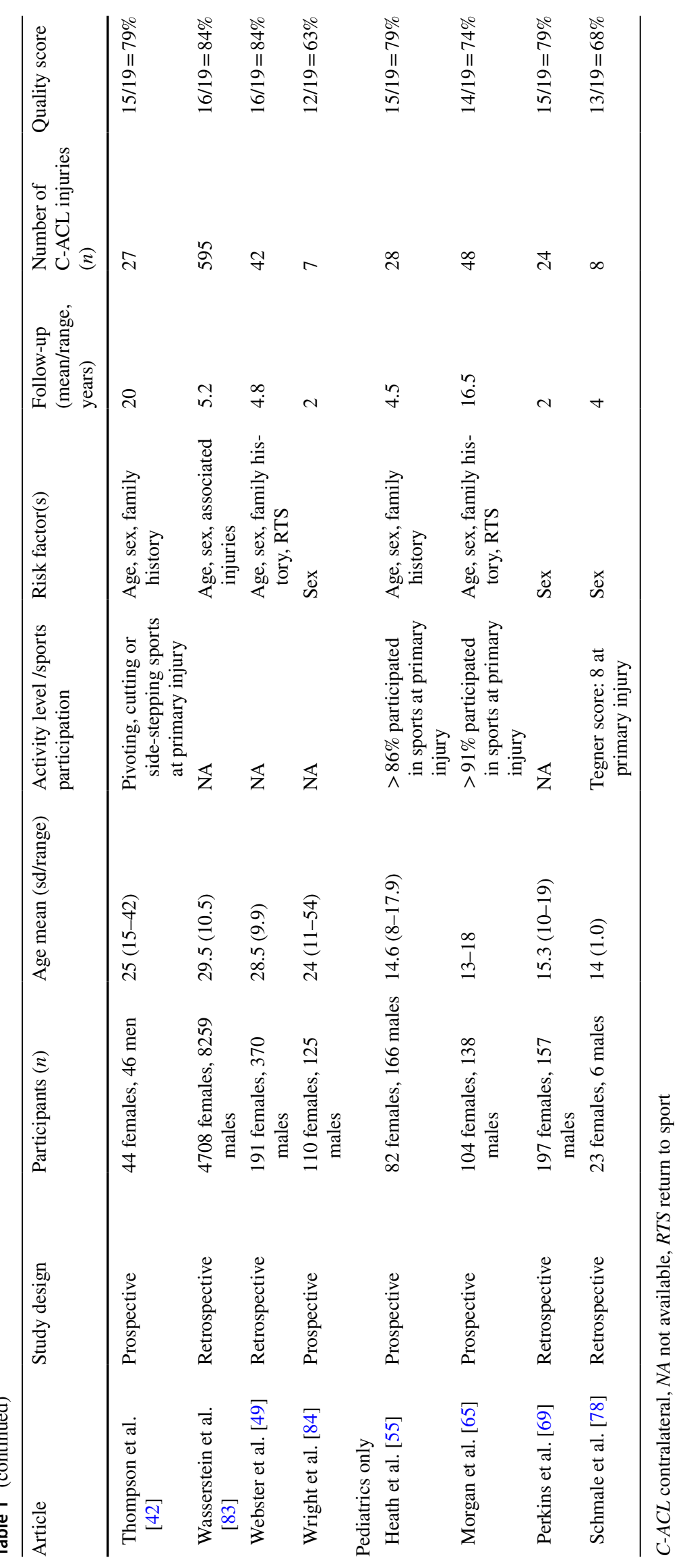




\begin{tabular}{|c|c|c|c|c|c|c|c|}
\hline Author \& Publication year & Population & & es for ea & & & Odds ratio and $95 \% \mathrm{Cl}$ & \\
\hline & & $\begin{array}{c}\text { Odds } \\
\text { ratio }\end{array}$ & $\begin{array}{l}\text { Lower } \\
\text { limit }\end{array}$ & $\begin{array}{l}\text { Upper } \\
\text { limit }\end{array}$ & & & \\
\hline Annear et al. 2019 [35] & $A / P$ & 0.78 & 0.12 & 5.26 & & & \\
\hline Bourke et al. 2012 [51] & $\mathrm{A} / \mathrm{P}$ & 1.20 & 0.75 & 1.91 & & & \\
\hline Fältström et al. 2016 [44] & $A / P$ & 1.35 & 1.15 & 1.59 & & & \\
\hline Grassi et al. 2020 [8] & $A / P$ & 0.36 & 0.08 & 1.58 & & & \\
\hline Kaeding et al. 2015 [55] & $\mathrm{A} / \mathrm{P}$ & 1.52 & 0.91 & 2.54 & & & \\
\hline Leys et al. 2012 [59] & $A / P$ & 0.67 & 0.23 & 1.93 & & & \\
\hline Maletis et al. 2015 [61] & $A / P$ & 1.78 & 1.43 & 2.21 & & & \\
\hline Mardani-Kivi et al. 2019 [62] & $\mathrm{A} / \mathrm{P}$ & 3.08 & 1.92 & 4.94 & & & \\
\hline McPherson et al. 2019 [33] & $A / P$ & 2.43 & 0.93 & 6.37 & & & \\
\hline Mohtadi et al. 2016 [63] & $\mathrm{A} / \mathrm{P}$ & 1.84 & 0.68 & 4.95 & & & \\
\hline Paterno et al. 2014 [46] & $A / P$ & 2.40 & 0.49 & 11.77 & & & \\
\hline Pinczewski et al. 2007 [70] & $A / P$ & 0.96 & 0.56 & 1.63 & & & \\
\hline Pujol et al. 2007 [71] & $A / P$ & 1.09 & 0.43 & 2.75 & & & \\
\hline Rosenstiel et al. 2019 [72] & $A / P$ & 2.53 & 0.65 & 9.86 & & & \\
\hline Salmon et al. 2005 [73] & $\mathrm{A} / \mathrm{P}$ & 1.27 & 0.64 & 2.54 & & & \\
\hline Salmon et al. 2006 [75] & $A / P$ & 1.23 & 0.36 & 4.22 & & & \\
\hline Salmon et al. 2018 [74] & $A / P$ & 0.80 & 0.29 & 2.23 & & & \\
\hline Shelbourne et al. 1998 [78] & $A / P$ & 3.22 & 1.42 & 7.28 & & & \\
\hline Shelbourne et al. 2009 [79] & $A / P$ & 2.19 & 1.37 & 3.51 & & & \\
\hline Thompson et al. 2015 [41] & $\mathrm{A} / \mathrm{P}$ & 0.68 & 0.26 & 1.78 & & & \\
\hline Wasserstein et al. 2013 [82] & $\mathrm{A} / \mathrm{P}$ & 1.20 & 1.02 & 1.42 & & & \\
\hline Webster et al. 2014 [48] & $A / P$ & 0.52 & 0.24 & 1.11 & & & \\
\hline Wright et al. 2007 [83] & $\mathrm{A} / \mathrm{P}$ & 2.90 & 0.55 & 15.28 & & & \\
\hline Heath et al. 2019 [54] & $\mathrm{P}$ & 1.19 & 0.54 & 2.64 & & & \\
\hline Morgan et al. 2016 [64] & $\mathrm{P}$ & 0.54 & 0.26 & 1.12 & & & \\
\hline Perkins et al. 2019 [68] & $\mathrm{P}$ & 2.02 & 0.82 & 5.01 & & & \\
\hline Salmon et al. 2018 [74] & $\mathrm{P}$ & 0.28 & 0.04 & 1.92 & & & \\
\hline Schmale et al. 2014 [77] & $\mathrm{P}$ & 2.19 & 0.21 & 22.34 & & & \\
\hline & & 1.35 & 1.14 & 1.61 & & & \\
\hline$I^{2}=19.5$ & & & & & & & \\
\hline & & & & & & Females & \\
\hline
\end{tabular}

Fig. 2 Sex differences in the odds of sustaining a C-ACL injury (C-ACL injury $n=2259$, controls $n=57189$ ). A/p adults and pediatric; $p$ pediatric, $N A$ not available

\subsubsection{Age}

Based on seven studies, the odds for sustaining a C-ACL injury decreased by 0.27 for every yearly increase in age (OR 0.73, 95\% CI 0.59-0.90, $p=0.003$, C-ACL injury $n=1$ 052, controls $n=38$ 896). Similarly, based on two studies, the odds of sustaining a C-ACL injury was 2.35 times higher for those younger than 20 years compared to those older than 20 years (OR 2.35, 95\% CI 2.00-2.77, $p<0.001$, C-ACL injury $n=637$, controls $n=12530$ ) and, based on six studies, 2.42 times higher for those younger than 18 years compared to those older than 18 years (OR 2.42, 95\% CI $1.51-3.88, p<0.001$, C-ACL injury $n=271$, controls $n=2$ 412 ) at the time of initial ACL injury (Fig. 3).

\subsubsection{Body Mass Index}

Based on two studies, there was no association between $\mathrm{BMI}$ as a continuous variable and the odds of sustaining a C-ACL injury (OR 1.0, 95\% CI 0.82-1.22, $p=0.996$, C-ACL injury $n=329$, controls $n=16794$ ). In contrast, when dichotomized, a $\mathrm{BMI}<25$ compared to $\geq 25$ was associated with increased odds for subsequent C-ACL injury (OR 2.73, 95\% CI 1.73-4.36, $p<0.001$, C-ACL injury $n=102$, controls $n=1080$ ) (Fig. 4).

\subsubsection{Family History}

Based on nine studies, there was a two-fold increase in the odds of sustaining a C-ACL injury with a positive family history of ACL injury (OR 2.07, 95\% CI 1.54-2.80, $p<0.001$, C-ACL injury $n=246$, controls $n=2$ 590) (Fig. 5).

\subsubsection{Smoking Status}

Based on three studies, there was no effect of being a smoker compared to being a non-smoker on the odds of sustaining a C-ACL injury (OR 1.34, 95\% CI 0.67-2.67, $p=0.411$, C-ACL injury $n=46$, controls $n=2$ 629) (Fig. 6). 


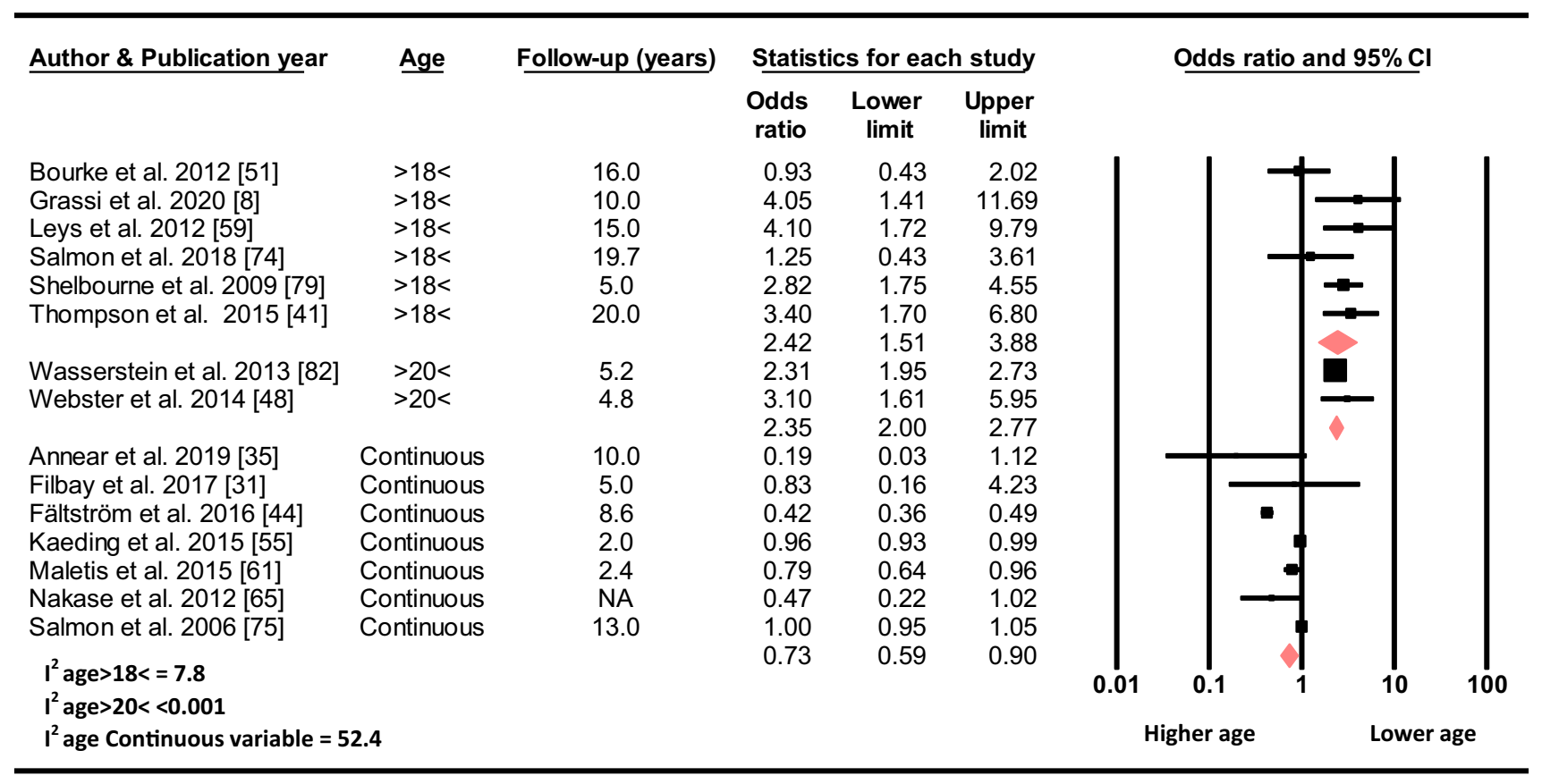

Fig. 3 Differences in the odds of sustaining a C-ACL injury between those older and younger than 18 (C-ACL injury $n=271$, controls $n=2412$ ) and 20 (C-ACL injury $n=637$, controls $n=12$ 530) years, respectively, and age as a continuous variable (C-ACL injury $n=1$ 052, controls $n=38$ 896). NA not available

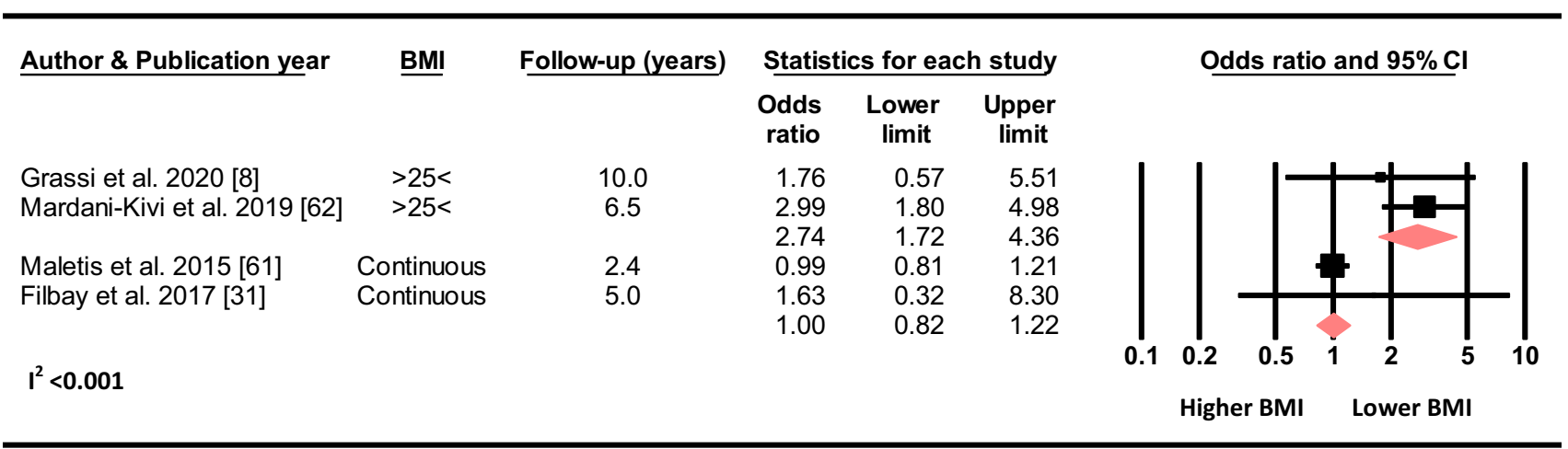

Fig. 4 Differences in the odds of sustaining a C-ACL injury between those with a BMI $>25$ compared to $<25$ (C-ACL injury $n=102$, controls $n=1080)$ and BMI as a continuous variable (C-ACL injury $n=329$, controls $n=16794$ )

\subsubsection{Geometrics}

Based on two studies, there was a decrease of 0.58 in the odds of sustaining a C-ACL injury with an increase in the ratio of the width of the intercondylar notch and the width of the distal femur (OR 0.42, 95\% CI 0.26-0.69, C-ACL injury $n=84$, controls $n=1319$ ) (Fig. 7).

\subsubsection{Associated Injuries to the Ipsilateral Knee}

Based on four studies, the meta-analysis showed that having a concomitant meniscal injury increased the odds of a C-ACL injury (OR 1.21, 95\% CI 1.03-1.42, $p=0.020$, C-ACL injury $n=719$, controls $n=22475$ ), whereas, based on 5 studies, having meniscal surgery (OR $0.97,95 \%$ CI 


\section{Author \& Publication year}

Bourke et al. 2012 [51]

Goshima et al. 2014 [53]

Mardani-Kivi et al. 2019 [62]

Salmon et al. 2005 [73]

Salmon et al. 2018 [74]

Thompson et al. 2015 [41]

Webster et al. 2014 [48]

Heath et al. 2019 [54]

Morgan et al. 2016 [64]

$I^{2}<0.001$

\section{Statistics for each study

$\begin{array}{ccc}\text { Odds } & \text { Lower } & \text { Upper } \\ \text { ratio } & \text { limit } & \text { limit }\end{array}$ \\ limit}

$\begin{array}{rc}\text { A/P } & 16.000 \\ \text { A/P } & 2.000 \\ \text { A/P } & 6.500 \\ \text { A/P } & 5.000 \\ \text { A/P } & 19.700 \\ \text { A/P } & 20.000 \\ \text { A/P } & 4.800 \\ \text { P } & 4.500 \\ \text { P } & 16.500\end{array}$

1.84

1.40

3.21

1.10

2.22

1.10

2.20

2.41

3.97

2.07

Odds ratio and $95 \% \mathrm{Cl}$

3.00
3.72
5.21
2.46
5.72
2.46
4.31
9.26
8.07
2.80

$\mid$

0.10 .2

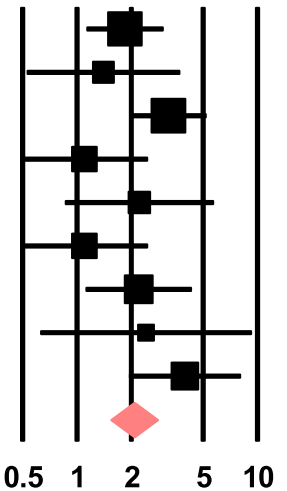

No Family history Family history

Fig. 5 Differences in the odds of sustaining a C-ACL injury between those with a family history of ACL injury and those without (C-ACL injury $n=246$, controls $n=2590)$. $A / p$ adults and pediatric, $p$ pediatric

\begin{tabular}{|c|c|c|c|c|}
\hline \multicolumn{2}{|c|}{ Author \& Publication year Follow-up (years) } & \multicolumn{3}{|c|}{ Statistics for each study } \\
\hline & & $\begin{array}{c}\text { Odds } \\
\text { ratio }\end{array}$ & $\begin{array}{l}\text { Lower } \\
\text { limit }\end{array}$ & $\begin{array}{c}\text { Upper } \\
\text { limit }\end{array}$ \\
\hline Filbay et al. 2017 [31] & 5.0 & 1.76 & 0.28 & 11.03 \\
\hline Grassi et al. 2020 [8] & 10.0 & 1.72 & 0.66 & 4.45 \\
\hline Kaeding et al. 2015 [55] & 2.0 & 0.80 & 0.24 & 2.67 \\
\hline & & 1.34 & 0.67 & 2.67 \\
\hline
\end{tabular}

$1^{2}<0.001$

\section{Odds ratio and $95 \% \mathrm{CI}$}
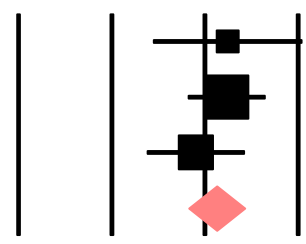

$\begin{array}{lllll}0.01 & 0.1 & 1 & 10 & 100\end{array}$

Fig. 6 Difference in the odds of sustaining a C-ACL injury between smokers and non-smokers (C-ACL injury $n=46$, controls $n=2$ 629)

$0.71-1.33, p=0.859$, C-ACL injury $n=1321$, controls $n=32738$ ) did not. A meta-analysis of four studies showed that concomitant cartilage injury decreased the odds of sustaining a C-ACL injury (OR 0.83, 95\% CI 0.69-1.00, $p=0.050, \mathrm{C}$-ACL injury $n=1198$, controls $n=31708$ ) (Fig. 8).

\subsubsection{Timing of Reconstruction}

Based on two studies, receiving reconstruction of the primary ACL injury $\leq 3$ months post injury increased the odds of sustaining a C-ACL injury (OR 1.65, 95\% CI 1.32-2.06, $p<0.001$, C-ACL injury $n=571$, controls $n=17842$ ) (Fig. 9).

\subsubsection{Activity Level and Sports Participation}

Based on two studies, Tegner activity level prior to the initial injury was not associated with the odds of sustaining a C-ACL injury (OR 1.29, 95\% CI 0.74-2.22, $p=0.368$, C-ACL injury $n=71$, controls $n=291$ ) (Fig. 10). 


\begin{tabular}{|c|c|c|c|c|c|}
\hline \multirow[t]{2}{*}{ Author \& Publication year } & \multirow[t]{2}{*}{$\underline{\text { Sex }}$} & \multirow[t]{2}{*}{ Follow-up (years) } & \multicolumn{3}{|c|}{ Statistics for each study } \\
\hline & & & $\begin{array}{l}\text { Odds } \\
\text { ratio }\end{array}$ & $\begin{array}{l}\text { Lower } \\
\text { limit }\end{array}$ & $\begin{array}{c}\text { Upper } \\
\text { limit }\end{array}$ \\
\hline Souryal et al. 1988 [80] & NA & NA & 0.39 & 0.22 & 0.68 \\
\hline Schickendantz et al. 1993 [76] & NA & 4.0 & 0.56 & 0.21 & 1.49 \\
\hline & & & 0.42 & 0.26 & 0.69 \\
\hline
\end{tabular}

Odds ratio and $95 \% \mathrm{CI}$

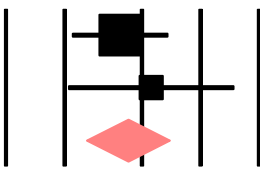

$\begin{array}{lllllll}0.1 & 0.2 & 0.5 & 1 & 2 & 5 & 10\end{array}$

$I^{2}<0.001$

Higher ratio

Lower ratio

Fig. 7 Differences in the odds of sustaining a C-ACL injury with increasing width of the intercondylar notch/width of the distal femur ratio (C-ACL injury $n=84$, controls $n=1319$ ). NA not available

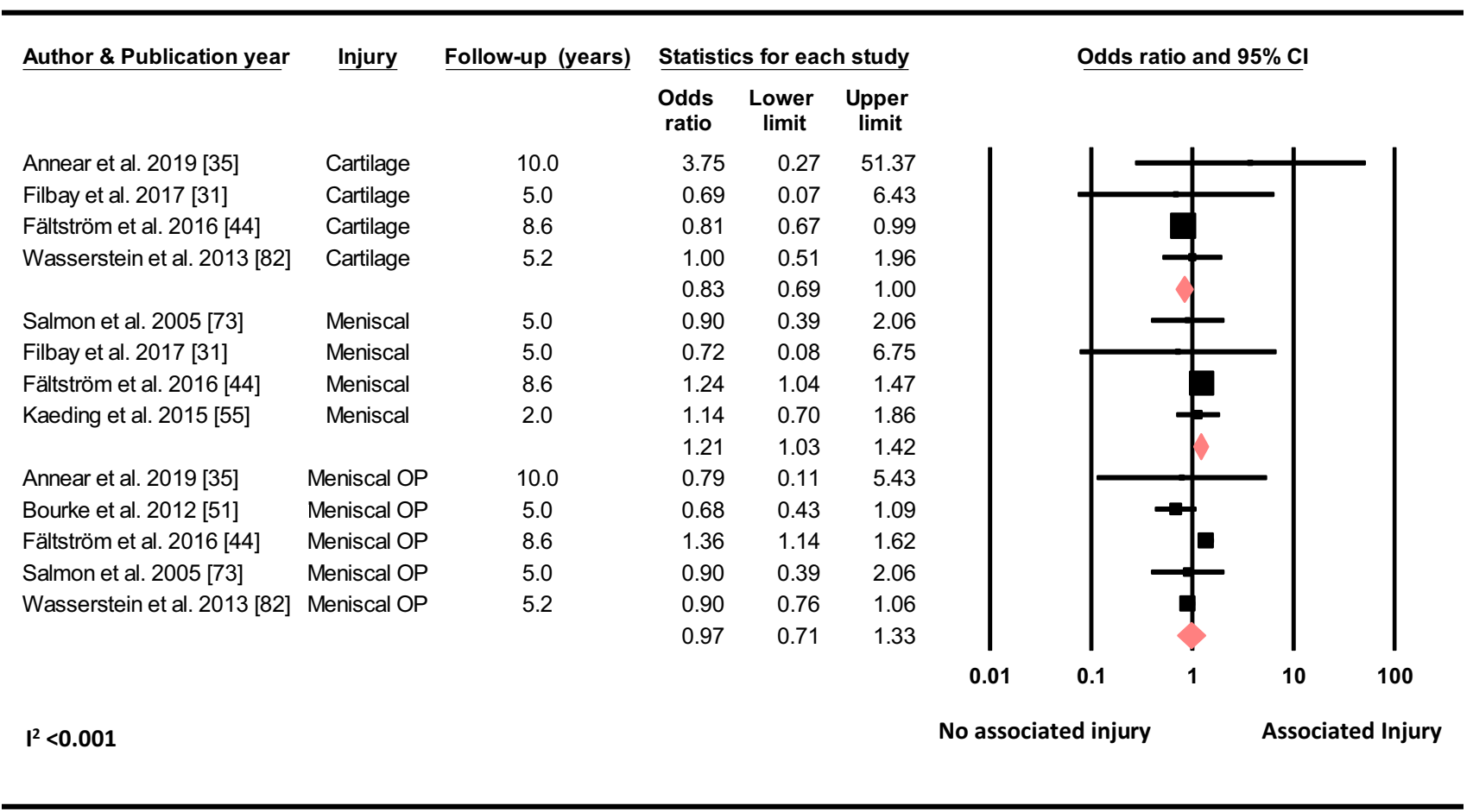

Fig. 8 Differences in the odds of sustaining a C-ACL injury between those with and without concomitant cartilage injury (C-ACL injury $n=1198$, controls $n=31,708$ ), meniscal injury (C-ACL injury

Based on six studies, returning to a high activity level/ sport (sports including cutting and pivoting) increased the odds of sustaining a C-ACL more than threefold compared to returning to a low activity level or not returning at all (OR $3.26,95 \%$ CI 2.10-5.06, $p<0.001$, C-ACL injury $n=327$, controls $n=4$ 256) (Fig. 10). $n=719$, controls $n=22475$ ) and meniscal surgery (C-ACL injury $n=1321$, controls $n=32738$ ). $O p$ surgery

Based on two studies, playing soccer at the time of primary injury did not increase the odds of sustaining a C-ACL compared to other sports (OR 2.01, 95\% CI 0.61-6.67, $p=0.252$, C-ACL injury $n=578$, controls $n=17$ 599) (Fig. 11). 


\begin{tabular}{|c|c|c|c|c|}
\hline \multirow[t]{2}{*}{ Author \& Publication year } & \multirow[t]{2}{*}{ Follow-up (years) } & \multicolumn{3}{|c|}{ Statistics for each study } \\
\hline & & $\begin{array}{c}\text { Odds } \\
\text { ratio }\end{array}$ & $\begin{array}{l}\text { Lower } \\
\text { limit }\end{array}$ & $\begin{array}{c}\text { Upper } \\
\text { limit }\end{array}$ \\
\hline Grassi et al. 2020 [8] & 10.0 & 1.08 & 0.37 & 3.13 \\
\hline Fältström et al. 2016 [44] & 8.6 & 1.68 & 1.34 & 2.11 \\
\hline & & 1.65 & 1.32 & 2.06 \\
\hline
\end{tabular}

Odds ratio and $95 \% \mathrm{Cl}$

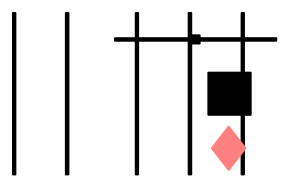

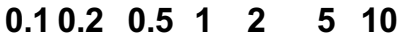

ACLR $>3$ moths $\quad$ ACLR $\leq 3$ months
Fig. 9 Differences in the odds of sustaining a C-ACL injury between those who performed the reconstruction $>3$ months and those who performed the reconstruction $\leq 3$ months post primary injury (C-ACL injury $n=571$, controls $n=17842$ ). ACLR anterior cruciate ligament reconstruction

\begin{tabular}{|c|c|c|c|c|c|c|c|}
\hline \multirow[t]{2}{*}{ Author \& Publication year } & \multirow[t]{2}{*}{ Population } & \multirow[t]{2}{*}{$\underline{\text { Sex }}$} & \multirow[t]{2}{*}{ Activity level } & \multirow[t]{2}{*}{ Follow-up (years) } & \multicolumn{3}{|c|}{ Statistics for each study } \\
\hline & & & & & $\begin{array}{c}\text { Odds } \\
\text { ratio }\end{array}$ & $\begin{array}{c}\text { Lower } \\
\text { limit }\end{array}$ & $\begin{array}{c}\text { Upper } \\
\text { limit }\end{array}$ \\
\hline Filbay et al. 2017 [31] & $A / P$ & $\mathrm{~F} / \mathrm{M}$ & Pre-injury & 5.0 & 2.65 & 0.52 & 13.52 \\
\hline \multirow[t]{2}{*}{ Fältström et al. 2013 [10] } & $\mathrm{A} / \mathrm{P}$ & $\mathrm{F} / \mathrm{M}$ & Pre-injury & NA & 1.17 & 0.66 & 2.09 \\
\hline & & & & & 1.28 & 0.74 & 2.22 \\
\hline Allen et al. 2016 [50] & A/P & $\mathrm{F}$ & RTS & 5.7 & 8.58 & 0.48 & 152.49 \\
\hline Bourke et al. 2012 [51] & $\mathrm{A} / \mathrm{P}$ & $\mathrm{F} / \mathrm{M}$ & RTS & 4.8 & 2.27 & 1.23 & 4.20 \\
\hline *Kaeding et al. 2015 [55] & $\mathrm{A} / \mathrm{P}$ & $\mathrm{F} / \mathrm{M}$ & RTS & 2.0 & 1.37 & 0.17 & 11.08 \\
\hline Kaeding et al. 2015 [55] & A/P & $\mathrm{F} / \mathrm{M}$ & RTS & 2.0 & 2.34 & 0.28 & 19.46 \\
\hline Kaeding et al. 2015 [55] & $\mathrm{A} / \mathrm{P}$ & $\mathrm{F} / \mathrm{M}$ & RTS & 2.0 & 2.29 & 0.28 & 18.56 \\
\hline Salmon et al. 2005 [73] & $\mathrm{A} / \mathrm{P}$ & $\mathrm{F} / \mathrm{M}$ & RTS & 5.0 & 10.63 & 3.22 & 35.12 \\
\hline Webster et al. 2014 [48] & $\mathrm{A} / \mathrm{P}$ & $\mathrm{F} / \mathrm{M}$ & RTS & 4.8 & 5.31 & 2.05 & 13.77 \\
\hline \multirow[t]{2}{*}{ Morgan et al. 2016 [64] } & $\mathrm{P}$ & $\mathrm{F} / \mathrm{M}$ & RTS & 16.5 & 2.42 & 0.97 & 6.04 \\
\hline & & & & & 3.26 & 2.10 & 5.06 \\
\hline
\end{tabular}

$1^{2}<0.001$

Odds ratio and $95 \% \mathrm{Cl}$

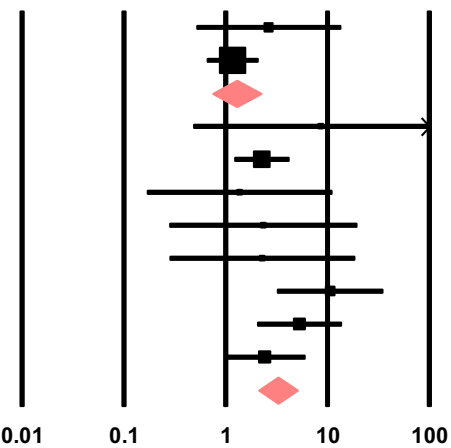

Low activity level High activity level
Fig. 10 Differences in the odds of sustaining a C-ACL injury according to pre-primary injury activity level (Pre-injury) (C-ACL injury $n=71$, controls $n=291$ ) and between those who returned to a high activity level/sport (RTS) and those who did not (C-ACL injury

A meta-analysis of two studies showed no increased odds of sustaining a C-ACL with returning to sport $\leq 6$ months post primary ACLR compared to more than 6 months (OR $1.89,95 \%$ CI $0.44-8.08, p=0.392, \mathrm{C}-\mathrm{ACL}$ injury $n=92$, controls $n=1475$ ) (Fig. 12).

\subsubsection{Subgroup Analysis of Pediatric Populations}

3.2.10.1 Sex Based on five studies, there was no sex difference in the risk of sustaining a C-ACL (OR 0.97, 95\% $n=327$, controls $n=4256) . A / p$ adults and pediatric, $F$ females, $M$ males, NA not available. "Asterisk" Kaeding et al. reported for three different cohorts, returning to basketball, football and soccer, respectively

CI $0.50-1.89, p=0.937$, C-ACL injury $n=130$, controls $n=754$ ) (Online resource 3 , Fig. 1).

3.2.10.2 Age Based on two studies, there was no difference in the risk of sustaining C-ACL between those younger than 14 years compared to those 14-18 years old (OR 0.77, 95\% CI $0.23-2.64, p=0.688$, C-ACL injury $n=78$, controls $n=337$ ) (Online resource 3, Fig. 2).

3.2.10.3 Family History Based on two studies, there was an increased odds of sustaining a C-ACL with a family his- 
Author \& Publication year

Allen et al. 2016 [50]

Fältström et al. 2016 [44]

$\mathrm{F}$

F/M

$\underline{\text { Sex }}$

Follow-up (years)

Statistics for each study

Odds Lower Upper

ratio limit limit

4.30

1.23

1.37

1.04

13.52

2.01

0.61

1.46

6.67
Odds ratio and $95 \% \mathrm{Cl}$

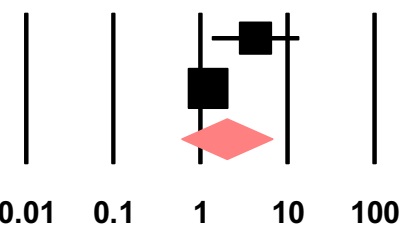

Other sports Soccer

$\mathrm{I}^{2}<0.001$

Fig. 11 Difference in the odds of sustaining a C-ACL injury between those who played soccer at the time of primary injury and those who played other sports (C-ACL injury $n=578$, controls $n=17$ 599). $F$ females, $M$ males



Fig. 12 Difference in the odds of sustaining a C-ACL injury between those who returned to sport $>6$ months post ACLR and those who returned to sport $<6$ months post ACLR (C-ACL injury $n=92$, controls $n=1475$ ). ACLR anterior cruciate ligament reconstruction, $R T S$ return to sport

tory of ACL injury (OR 3.56, 95\% CI 1.90-6.67, $p<0.001$, C-ACL injury $n=78$, controls $n=337$ ) (Online resource 3, Fig. 3).

\subsection{Sensitivity Analysis}

The sensitivity analyses revealed that excluding the studies that only included children or adolescents (sex, family history, return to high activity level) did not change the direction or significance of the results. Limiting the studies to those with a follow-up $\geq 2$ years did not change the direction or significance of the results for sex, family history, meniscal injury or return to a high activity level, whereas lower age at primary injury (continuous varable) did no longer increase the odds of sustaining a C-ACL injury (Online resource 4).

\subsection{Heterogeneity and Risk of Bias}

$\mathrm{I}^{2}$ ranged between $<0.001 \%$ and $19.5 \%$ for all meta-analyses except one (age as a continuous variable), indicating low heterogeneity between studies [86]. The analysis for age as a continuous variable, however, had an $\mathrm{I}^{2}$ of $52.4 \%$, indicating moderate heterogeneity [86].

The quality of the included studies ranged from 53 to $95 \%$ with a mean score of $77.3 \%$, indicating a generally high methodological quality (Online resource 5, Table 1). Sex was the only variable for which more than ten articles were included in the meta-analysis and a funnel plot with trim and fill imputations was eligible. The funnel plot showed no difference in effect size if the apparent biases were removed, indicating no publication bias for sex as a risk factor for C-ACL [25] (Online resource 5, Fig. 1). 


\section{Discussion}

In this systematic review with meta-analysis, we found that female sex, younger age $(<18), \mathrm{BMI}<25$, a family history of ACL injury, femoral geometrics, concomitant meniscal injury, reconstruction of primary ACL injury perfomed within 3 months after injury, and returning to a high activity level (highest odds), were all independently associated with increased odds of sustaining a subsequent C-ACL injury. The analysis revealed no influence of smoking status, pre-injury activity level, playing soccer compared to other sports or timing of return to sport on the odds for sustaining a C-ACL injury. Few studies were identified that investigated sensorimotor and neuromuscular factors, such as proprioception, muscle strength, muscle activation patterns and/or kinematics and kinetics as risk factors for C-ACL injury and meta-analyses were, therefore, not possible.

Females have previously been reported to have about three times higher risk of sustaining a primary ACL injury compared to males [1, 87-90]. The current meta-analysis, including 59448 individuals, suggests females to have $35 \%$ higher odds (OR 1.35) of sustaining a subsequent C-ACL injury compared to their male counterparts, which is a substantially lower risk compared to that of primary injury. Several hormonal, neuromuscular and biomechanical risk factors have been proposed to contribute to the apparent sex difference in primary ACL injury rate. For example, the menstrual cycle and the use of contraceptives have been associated with ACL injury risk [91]. Furthermore, females seem to exhibit greater knee joint laxity, altered hip and knee muscle activation patterns as well as decreased neuromuscular control of the trunk and hip compared to males, which may contribute to a greater injury risk [16]. Females both with and without ACL injuries also perform functional tasks with greater knee valgus, a movement pattern commonly associated with knee injury risk [92], compared to males [23, 93]. On the other hand, the sub-group analysis for studies including only children and/or adolescents showed no sex difference for the risk of sustaining a C-ACL injury in individuals younger than 19 years. This result may be explained by the fact that the aforementioned differences in biomechanics and neuromuscular function seem to develop through maturation. Shultz et al. [94]., reported that while females and males presented with similar anatomical features in early maturation stages, females developed more valgus aligned knee postures and increased knee laxity during growth, whereas males moved towards a varus aligned position and decreased knee laxity. That the C-ACL injury risk for females compared to males seems to be much less compared to primary injury may potentially be explained by the fact that some of the risk factors for primary injury may not be relevant for C-ACL injury, in addition to that some risk factors for primary injury, such as family history [54] and kinetic and postural stability deficits [30] are present in both males and females who sustain the first injury. As no studies which included hormonal cyclic variations, knee joint laxity or neuromuscular factors, such as muscle strength and musle activation patterns were eligible for meta-analysis in the current review, it cannot be ruled out that such sex-specific risk factors for primary injury may also contribute to an increased risk of subsequent C-ACL injuries in adult females.

The result from the present meta-analysis supports the findings of a previous review that reported an increased rate of secondary ACL injuries (ipsi-lateral and contra-lateral injuries combined) in individuals younger than 25 years [9]. Similarly, we found the odds of sustaining a C-ACL injury in those younger than 18 and 20 years to be twice the odds of those older than 18 and 20 years, respectively. There are major development regarding anatomical, biomechanical and neuromuscular features as well as changes in joint laxity still during the adolescent period, which may contribute to the risk of injury in this age [94, 95]. The fact that we found no age difference ( $<14$ vs. $>14-18$ years) in the odds of sustaining a C-ACL injury in a group consisting of only children and adolescents may support this theory. In the meta-analysis, returning to a high activity level was associated with a threefold increase in the odds of sustaining a C-ACL injury. Another explanation for the association between younger age and injury risk may be that younger individuals tend to return earlier, more often and to a higher activity level compared to their older peers [40, 49, 80].

To have a family history of ACL injury was associated with a twofold increase in the odds of sustaining a C-ACL injury in the pooled analysis for adults and younger individuals, and with a threefold increase in individuals younger than 18 years. The influence of genes and associated polymorphisms has previously been suggested to play a role for knee injury [96]. Results from different studies are, however, conflicting and there is currently no convincing evidence that specific genotypes will pre-dispose individuals to ACL injury [96-100]. Genetic variations in the form of inherited anatomical or biomechanical alterations may, however, be important for injury risk. Salmon et al. [74] reported a Hazard ratio of 7.3 to sustain a C-ACL injury in those with a tibial slope of $\geq 12^{\circ}$ compared to those with a tibial slope $<12^{\circ}$ (Online resource 2 ). A recent meta-analysis found that individuals with ACL injury had smaller femoral notch width and lower notch width index compared to noninjured individuals [101]. Our meta-analysis also revealed that individuals with a higher width of the intercondylar notch/width of the distal femur ratio had lower odds of sustaining a C-ACL injury. Another explanation for the relation between family history of ACL injury and the risk of C-ACL injury may be related to an inherited culture of 
sports participation. In a study by Goshima et al. [54], all family members of the study participants that had a history of ACL injury were injured during sports and $65 \%$ were injured during the same sport as the their relative included in the study. Taken together, it is possible that the explanation for the association between family history and C-ACL injury is partly attributed to genetic variations in the morphology of the knee and/or a mutual familial interest for sport participation. Future studies are, however, warranted to confirm this theory and to investigate possible associations between genetic variations in other physical characteristics and the risk of secondary injury.

In the current meta-analysis we found an increased odds of a C-ACL injury if the participant had a concomitant meniscal injury to the ipsilateral knee at the time of primary injury, whereas no such association was revealed if a meniscal surgery was performed with the primary reconstruction. Interestingly, individuals that had concomitant cartilage injury on the index knee had lower odds of sustaining a subsequent C-ACL injury. It may be speculated that individuals with severe meniscal damage which requires surgery and those with cartilage injury may not return to sport to the same extent and, thus, are less likely to put their knee at risk. However, given the low ORs $(\leq 1.21)$ and contradicting results, the clinical relevance of associated meniscal and cartilage injuries for further C-ACL injuries has still to be determined. Furthermore, a delay in surgery as well as a higher BMI have previously been linked to developing associated meniscal and cartilage injuries in individuals undergoing ACL reconstruction [102-104]. In the current meta-analysis, an early reconstruction ( $<3$ months vs. $\geq 3$ months) and a lower BMI ( $<25$ vs. $\geq 25)$ increased the odds of sustaining a C-ACL injury. Likewise, it is possible that individuals that perform an early surgery and/or have a lower BMI, are more likely to participate in sport and may also return earlier to sport than those with a delayed surgery and/or higher BMI and thereby increase the risk of a new injury. However, these assumptions need to be corroborated by further research.

Participation in high-risk sports which include cutting and pivoting movements, such as soccer, basketball and handball, is widely accepted to substantially increase the risk of ACL injuries [105]. In the current review, playing soccer compared to other sports at the time of primary injury did not increase the risk of subsequent C-ACL injury, whereas returning to a high activity level, irrespective of sport type, was associated with the highest odds (3.26) of sustaining a C-ACL injury. This indicates that returning to any kneedemanding sport will put the athlete at greater risk for subsequent injuries. However, in the articles on playing soccer compared to other sports, other sports were not clearly defined. If other sports also included sports involving cutting and pivoting, this may be an explanation for the lack of difference in injury risk between soccer and other sports. On the other hand, activity level prior to the primary injury was not associated with the risk for C-ACL injury. It should be noted that in the two studies that were included in the metaanalysis for pre-injury activity level, one reported a median Tegner activity level of 9 [10] and one reported approximately $80 \%$ of the participants to have a pre-injury Tegner of 8-9 [32]. This suggests that most participants in these studies participated in high-risk sports and consequently the narrow distribution may have influenced the result for this analysis.

There is conflicting evidence whether an early return to sport may increase the risk of subsequent ACL injuries (graft rupture or graft rupture and C-ACL injury combined) [106-108]. In the current review, timing of return to sport ( $<6$ months vs. $\geq 6$ months) did not affect the C-ACL injury rate. No studies were identified that investigated other time points of return to sports in relation to C-ACL injury specifically. It has been suggested that the risk for further injuries may not be explained by time alone but may rather be related to the individuals' functional capacity at the time of return to sport $[109,110]$. There is, however no clear evidence supporting that adequate functional capacity (i.e., passing certain return to sport criteria) will decrease the risk of reinjury $[109,110]$. A recent meta-analysis reported that passing such criteria may even increase the risk of secondary C-ACL injury [110]. Future studies are, thus, warranted in order to clarify the influence of neuromuscular function as well as different time points of return to sport on secondary ACL injuries.

Smoking status was not related to the risk of subsequent $\mathrm{C}-\mathrm{ACL}$ injury in this review. This is in line with studies showing no effect of smoking status and the risk of revision surgery after ACLR [111, 112]. Although smokers seem to have worse self-reported and clinical outcomes and increased risk of complications after ACLR [112], being a smoker seems not to influence the risk of further injury to either knee.

Most studies included in this review investigated risk factors related to demographics and/or sports participation, while studies on elements related to neuromuscularfunction as possible risk factors for sustaining a C-ACL injury are lacking. A few studies have previously pointed to a possible role of hip and knee movement patterns and moments during functional tasks, as well as hop performance, for the risk of sustaining second ACL injuries (graft rupture and C-ACL injury combined) $[30,39,113]$. There is nevertheless limited evidence for lower extremity strength as a contributing factor to C-ACL injury risk [53, 66] (Online resource 2). Given that demographic factors such as sex, age and family history cannot be changed, studies on risk factors that are modifiable are encouraged. The possibility of identifying factors that are modifiable by training will facilitate the design of 
rehabilitation protocols to better reduce the risk of secondary injuries following ACL injury.

A strength of this review is that we considered all studies for inclusion without restrictions relating to sex, age, sports participation or publication date, indicating high generalizability of our results. Additionally, the studies included were in general of high methodological quality and the separate meta-analyses included between 360 and 59,000 individuals. This review does nonetheless have some limitations. While we included all studies that reported C-ACL injuries, some studies used subsequent C-ACL reconstruction (mainly identified from surgical records) as their primary outcome, whereas some studies used subsequent C-ACL injury reported by the participants or by medical staff. It is likely that the use of C-ACL reconstruction as primary outcome underestimated the incidence of further knee injuries, which may have influenced the results in these included studies. Secondly, we pooled studies with different followups (6 months to 20 years) in the analyses. Several studies show that the time from primary reconstruction to subsequent C-ACL injury is often $3-4$ years $[8,52,73]$, indicating that studies with a follow-up of less than 3 years may not be able to capture all C-ACL injuries and consequently the results from such studies should be interpreted with caution. Our sensitivity analysis also showed that lower age (as a continuous variable) was no longer a risk factor for C-ACL injury if studies with a follow-up of $\leq 2$ years were excluded, whereas there were no differences in the result for other risk factors. Thirdly, to increase power, we pooled studies that included adults only, children only and those who pooled children and adults. It may be argued that the risk factors for children and adults are not the same. We did, however, perform both a sensitivity analysis, excluding studies on children and subgroup analysis including children only to account for these possible differences. Forth, two of the meta-analysis included only two studies each with a relatively low number of individuals with C-ACL injury, i.e., the analysis for pre-injury activity level $(n=71)$ and the analysis for timing of return to sport $(n=92)$. It has been suggested that there will be an increased risk of overestimating the effect when meta-analysis with a low number of events are performed [114]. Thus, some caution is needed when interpreting the result for pre-injury activity level and timing of return to sport. Fifth, although addressing relevant risk factors, a few articles could not be included in the meta-analyses due to being the only study assessing a specific variable or time point (e.g., different geometric variables and muscle strength pre/post reconstruction). To fully understand the role of potential risk factors for C-ACL injury, a more standardized methodological approach to the assessment of such factors should be considered in future studies. Finally, the risk of sustaining a C-ACL injury is multifactorial in nature and therefore cannot be explained simply by any single risk factor, and many of these are also interrelated. For example, it has been suggested that younger age is related to an earlier return to sport and higher activity level [40] as well as reflecting neuromuscular and anatomical characteristcs [94, 95]. Likewise, the analysis for sex difference may be influenced by associated genetic, anatomical and neuromuscular differences between the sexes [94]. In the current review we performed separate analyses for each risk factor. Meta-regressions, adjusting for confounding factors were not part of the aim of this study and indeed not even possible, due to limited availability of data and a limited number of studies in each analysis [115]. It is thus possible that the results for some of the factors that we found to be significant predictors for C-ACL injury in the meta-analyses would have been different if other variables had been poosible to take into account by applying a multifactorial model.

\section{Conclusion}

The results from this systematic review with meta-analysis including up to $\approx 59,000$ individuals reveal that return to a high activity level was the most prominent risk factor for sustaining a contra-lateral secondary ACL injury. Other independently associated factors were female sex, younger age and family history of ACL injury. All of these factors should be considered when screening for individuals that are at high risk of sustaining a C-ACL injury. Since most studies included in this review investigated demographic factors which are non-modifiable in nature, future studies are encouraged to investigate the contributing role of neuromuscular factors, such as muscle strength, muscle activation and movement patterns, that can be modified by training in order to target interventions which may better reduce secondary ACL injury risk.

\section{Declarations}

Funding Open Access funding provided by Umeå University. This review was funded by the Swedish Research Council for Sports Science (CIF 2019/9), The Gyllenstierna Krapperup's Foundation and Lennander's Foundation.

Conflict of Interest The authors of this study declare that they have no conflicts of interest relevant to the content of this review.

Ethical Approval Not applicable.

Consent to Participate Not applicable.

Consent for Publication Not applicable.

Availability of Data and Material The datasets used and/or analyzed during the current study are available from the corresponding author on reasonable request. 
Code Availability Not applicable.

Author Contributions Anna Cronström contributed to the design of the study, was responsible for collecting the data, was responsible for the analysis and interpretation of the data, and was in charge of writing the manuscript. Eva Tengaman contributed to the conception and design of the study, contributed to the collection of data, contributed to the analysis and interpretation of the data, and provided feedback on drafts of this paper. Charlotte K Häger contributed to the design of the study, contributed to the analysis and interpretation of the data and provided feedback on drafts of this paper. All authors read and approved the final manuscript.

Open Access This article is licensed under a Creative Commons Attribution 4.0 International License, which permits use, sharing, adaptation, distribution and reproduction in any medium or format, as long as you give appropriate credit to the original author(s) and the source, provide a link to the Creative Commons licence, and indicate if changes were made. The images or other third party material in this article are included in the article's Creative Commons licence, unless indicated otherwise in a credit line to the material. If material is not included in the article's Creative Commons licence and your intended use is not permitted by statutory regulation or exceeds the permitted use, you will need to obtain permission directly from the copyright holder. To view a copy of this licence, visit http://creativecommons.org/licenses/by/4.0/.

\section{References}

1. Walden M, Hagglund M, Werner J, Ekstrand J. The epidemiology of anterior cruciate ligament injury in football (soccer): a review of the literature from a gender-related perspective. Knee Surg Sports Traumatol Arthrosc. 2011;19(1):3-10.

2. Beynnon BD, Vacek PM, Newell MK, Tourville TW, Smith HC, Shultz SJ, et al. The effects of level of competition, sport, and sex on the incidence of first-time noncontact anterior cruciate ligament injury. Am J Sports Med. 2014;42(8):1806-12.

3. Tengman E, Brax Olofsson L, Nilsson KG, Tegner Y, Lundgren L, Hager CK. Anterior cruciate ligament injury after more than 20 years: I. Physical activity level and knee function. Scand J Med Sci Sports. 2014;24(6):e491-500.

4. Whittaker JL, Woodhouse LJ, Nettel-Aguirre A, Emery CA. Outcomes associated with early post-traumatic osteoarthritis and other negative health consequences 3-10 years following knee joint injury in youth sport. Osteoarthr Cartil. 2015;23(7):1122-9.

5. Ageberg E, Thomee R, Neeter C, Silbernagel KG, Roos EM. Muscle strength and functional performance in patients with anterior cruciate ligament injury treated with training and surgical reconstruction or training only: a two to five-year followup. Arthritis Rheum. 2008;59(12):1773-9.

6. Tengman E, Brax Olofsson L, Stensdotter AK, Nilsson KG, Häger CK. Anterior cruciate ligament injury after more than 20 years. II. Concentric and eccentric knee muscle strength. Scand J Med Sci Sports. 2014;24(6):e501-9.

7. Ardern CL, Taylor NF, Feller JA, Webster KE. Fifty-five per cent return to competitive sport following anterior cruciate ligament reconstruction surgery: an updated systematic review and metaanalysis including aspects of physical functioning and contextual factors. Br J Sports Med. 2014;48(21):1543-52.

8. Grassi A, Macchiarola L, Lucidi GA, Stefanelli F, Neri M, Silvestri A, et al. More than a 2-fold risk of contralateral anterior cruciate ligament injuries compared with ipsilateral graft failure 10 years after primary reconstruction. Am J Sports Med. 2020. https://doi.org/10.1177/0363546519893711.
9. Wiggins AJ, Grandhi RK, Schneider DK, Stanfield D, Webster KE, Myer GD. Risk of secondary injury in younger athletes after anterior cruciate ligament reconstruction: a systematic review and meta-analysis. Am J Sports Med. 2016;44(7):1861-76.

10. Fältstrom A, Hagglund M, Kvist J. Patient-reported knee function, quality of life, and activity level after bilateral anterior cruciate ligament injuries. Am J Sports Med. 2013;41(12):2805-13.

11. Swärd P, Kostogiannis I, Roos H. Risk factors for a contralateral anterior cruciate ligament injury. Knee Surg Sports Traumatol Arthrosc. 2010;18(3):277-91.

12. Sundemo D, Hamrin Senorski E, Karlsson L, Horvath A, JuulKristensen B, Karlsson J, et al. Generalised joint hypermobility increases ACL injury risk and is associated with inferior outcome after ACL reconstruction: a systematic review. BMJ Open Sport Exerc Med. 2019;5(1):e000620.

13. Evans KN, Kilcoyne KG, Dickens JF, Rue JP, Giuliani J, Gwinn $\mathrm{D}$, et al. Predisposing risk factors for non-contact ACL injuries in military subjects. Knee Surg Sports Traumatol Arthrosc. 2012;20(8):1554-9.

14. Nilstad A, Andersen TE, Bahr R, Holme I, Steffen K. Risk factors for lower extremity injuries in elite female soccer players. Am J Sports Med. 2014;42(4):940-8.

15. Price MJ, Tuca M, Cordasco FA, Green DW. Nonmodifiable risk factors for anterior cruciate ligament injury. Curr Opin Pediatr. 2017;29(1):55-64.

16. Hewett TE, Myer GD, Ford KR, Paterno MV, Quatman CE. Mechanisms, prediction, and prevention of ACL injuries: Cut risk with three sharpened and validated tools. J Orthop Res. 2016;34(11):1843-55.

17. Di Stasi S, Myer GD, Hewett TE. Neuromuscular training to target deficits associated with second anterior cruciate ligament injury. J Orthop Sports Phys Ther. 2013;43(11):777-92, a1-11.

18. Goerger BM, Marshall SW, Beutler AI, Blackburn JT, Wilckens $\mathrm{JH}$, Padua DA. Anterior cruciate ligament injury alters preinjury lower extremity biomechanics in the injured and uninjured leg: the JUMP-ACL study. Br J Sports Med. 2015;49(3):188-95.

19. Moher D, Liberati A, Tetzlaff J, Altman DG. Preferred reporting items for systematic reviews and meta-analyses: the PRISMA statement. PLoS Med. 2009;6(7):e1000097.

20. Liberati A, Altman DG, Tetzlaff J, Mulrow C, Gotzsche PC, Ioannidis JP, et al. The PRISMA statement for reporting systematic reviews and meta-analyses of studies that evaluate health care interventions: explanation and elaboration. PLoS Med. 2009;6(7):e1000100.

21. Lento PH, Akuthota V. Meniscal injuries: a critical review. J Back Musculoskelet Rehabil. 2000;15(2):55-62.

22. Cronström A, Creaby MW, Nae J, Ageberg E. Modifiable factors associated with knee abduction during weight-bearing activities: a systematic review and meta-analysis. Sports Med. 2016;46(11):1647-62.

23. Cronstrom A, Creaby MW, Nae J, Ageberg E. Gender differences in knee abduction during weight-bearing activities: a systematic review and meta-analysis. Gait Posture. 2016;49:315-28.

24. Downs SH, Black N. The feasibility of creating a checklist for the assessment of the methodological quality both of randomised and non-randomised studies of health care interventions. J Epidemiol Community Health. 1998;52(6):377-84.

25. Duval S, Tweedy R. A nonparametric "trim and fill method" of accounting for publication bias in meta-analyses. J Am Stat Assoc. 2000;95:89-98.

26. Ioannidis JP, Trikalinos TA. The appropriateness of asymmetry tests for publication bias in meta-analyses: a large survey. CMAJ. 2007;176(8):1091-6.

27. Dekker TJ, Godin JA, Dale KM, Garrett WE, Taylor DC, Riboh JC. Return to sport after pediatric anterior cruciate ligament 
reconstruction and its effect on subsequent anterior cruciate ligament injury. J Bone Jt Surg Am. 2017;99(11):897-904.

28. Krosshaug T, Steffen K, Kristianslund E, Nilstad A, Mok KM, Myklebust G, et al. The vertical drop jump is a poor screening test for ACL injuries in female elite soccer and handball players: a prospective cohort study of 710 athletes. Am J Sports Med. 2016;44(4):874-83.

29. Kamath GV, Murphy T, Creighton RA, Viradia N, Taft TN, Spang JT. Anterior cruciate ligament injury, return to play, and reinjury in the elite collegiate athlete: analysis of an NCAA Division I Cohort. Am J Sports Med. 2014;42(7):1638-43.

30. Paterno MV, Schmitt LC, Ford KR, Rauh MJ, Myer GD, Huang $\mathrm{B}$, et al. Biomechanical measures during landing and postural stability predict second anterior cruciate ligament injury after anterior cruciate ligament reconstruction and return to sport. Am J Sports Med. 2010;38(10):1968-78.

31. Schilaty ND, Nagelli C, Bates NA, Sanders TL, Krych AJ, Stuart MJ, et al. Incidence of second anterior cruciate ligament tears and identification of associated risk factors from 2001 to 2010 using a geographic database. Orthop J Sports Med. 2017;5(8):2325967117724196.

32. Filbay SR, Roos EM, Frobell RB, Roemer F, Ranstam J, Lohmander LS. Delaying ACL reconstruction and treating with exercise therapy alone may alter prognostic factors for 5-year outcome: an exploratory analysis of the KANON trial. Br J Sports Med. 2017;51(22):1622-9.

33. Hettrich CM, Dunn WR, Reinke EK, Spindler KP. The rate of subsequent surgery and predictors after anterior cruciate ligament reconstruction: 2- and 6-year follow-up results from a multicenter cohort. Am J Sports Med. 2013;41(7):1534-40.

34. McPherson AL, Feller JA, Hewett TE, Webster KE. Psychological readiness to return to sport is associated with second anterior cruciate ligament injuries. Am J Sports Med. 2019;47(4):857-62.

35. Sonnery-Cottet B, Thaunat M, Freychet B, Pupim BH, Murphy $\mathrm{CG}$, Claes S. Outcome of a combined anterior cruciate ligament and anterolateral ligament reconstruction technique with a minimum 2-year follow-up. Am J Sports Med. 2015;43(7):1598-605.

36. Annear PT, Rohr EJ, Hille DM, Gohil S, Ebert JR. No clinical difference in 10-year outcomes between standard and minimal graft debridement techniques in patients undergoing anterior cruciate ligament reconstruction using autologous hamstrings: a randomized controlled trial. Knee Surg Sports Traumatol Arthrosc. 2019;27(2):516-23.

37. Wasserstein D, Huston LJ, Nwosu S, Kaeding CC, Parker $\mathrm{RD}$, Wright RW, et al. KOOS pain as a marker for significant knee pain two and six years after primary ACL reconstruction: a Multicenter Orthopaedic Outcomes Network (MOON) prospective longitudinal cohort study. Osteoarthr Cartil. 2015;23(10):1674-84

38. Zaffagnini S, Marcheggiani Muccioli GM, Grassi A, Roberti di Sarsina T, Raggi F, Signorelli C, et al. Over-the-top ACL reconstruction plus extra-articular lateral tenodesis with hamstring tendon grafts: prospective evaluation with 20-year minimum follow-up. Am J Sports Med. 2017;45(14):3233-42.

39. Paterno MV, Huang B, Thomas S, Hewett TE, Schmitt LC. Clinical factors that predict a second ACL injury after ACL reconstruction and return to sport: preliminary development of a clinical Decision Algorithm. Orthop J Sports Med. 2017;5(12):2325967117745279.

40. Brophy RH, Schmitz L, Wright RW, Dunn WR, Parker RD, Andrish JT, et al. Return to play and future ACL injury risk after ACL reconstruction in soccer athletes from the Multicenter Orthopaedic Outcomes Network (MOON) group. Am J Sports Med. 2012;40(11):2517-22.

41. Paterno MV, Kiefer AW, Bonnette S, Riley MA, Schmitt LC, Ford KR, et al. Prospectively identified deficits in sagittal plane hip-ankle coordination in female athletes who sustain a second anterior cruciate ligament injury after anterior cruciate ligament reconstruction and return to sport. Clin Biomech (Bristol, Avon). 2015;30(10):1094-101.

42. Thompson S, Salmon L, Waller A, Linklater J, Roe J, Pinczewski L. Twenty-year outcomes of a longitudinal prospective evaluation of isolated endoscopic anterior cruciate ligament reconstruction with patellar tendon autografts. Am J Sports Med. 2015;43(9):2164-74.

43. Thompson SM, Salmon LJ, Waller A, Linklater J, Roe JP, Pinczewski LA. Twenty-year outcome of a longitudinal prospective evaluation of isolated endoscopic anterior cruciate ligament reconstruction with patellar tendon or hamstring autograft. Am J Sports Med. 2016;44(12):3083-94.

44. Hui C, Salmon LJ, Kok A, Maeno S, Linklater J, Pinczewski LA. Fifteen-year outcome of endoscopic anterior cruciate ligament reconstruction with patellar tendon autograft for "isolated" anterior cruciate ligament tear. Am J Sports Med. 2011;39(1):89-98.

45. Fältstrom A, Hagglund M, Magnusson H, Forssblad M, Kvist J. Predictors for additional anterior cruciate ligament reconstruction: data from the Swedish national ACL register. Knee Surg Sports Traumatol Arthrosc. 2016;24(3):885-94.

46. Webster KE, Feller JA. Exploring the high reinjury rate in younger patients undergoing anterior cruciate ligament reconstruction. Am J Sports Med. 2016;44(11):2827-32.

47. Paterno MV, Rauh MJ, Schmitt LC, Ford KR, Hewett TE. Incidence of second ACL injuries 2 years after primary ACL reconstruction and return to sport. Am J Sports Med. 2014;42(7):1567-73.

48. Andernord D, Desai N, Bjornsson H, Gillen S, Karlsson J, Samuelsson K. Predictors of contralateral anterior cruciate ligament reconstruction: a cohort study of 9061 patients with 5-year follow-up. Am J Sports Med. 2015;43(2):295-302.

49. Webster KE, Feller JA, Leigh WB, Richmond AK. Younger patients are at increased risk for graft rupture and contralateral injury after anterior cruciate ligament reconstruction. Am J Sports Med. 2014;42(3):641-7.

50. Paterno MV, Rauh MJ, Schmitt LC, Ford KR, Hewett TE. Incidence of contralateral and ipsilateral anterior cruciate ligament (ACL) injury after primary ACL reconstruction and return to sport. Clin J Sport Med. 2012;22(2):116-21.

51. Allen MM, Pareek A, Krych AJ, Hewett TE, Levy BA, Stuart MJ, et al. Are female soccer players at an increased risk of second anterior cruciate ligament injury compared with their athletic peers? Am J Sports Med. 2016;44(10):2492-8.

52. Bourke HE, Salmon LJ, Waller A, Patterson V, Pinczewski LA. Survival of the anterior cruciate ligament graft and the contralateral ACL at a minimum of 15 years. Am J Sports Med. 2012;40(9):1985-92.

53. Davey AP, Vacek PM, Caldwell RA, Slauterbeck JR, GardnerMorse MG, Tourville TW, et al. Risk factors associated with a noncontact anterior cruciate ligament injury to the contralateral knee after unilateral anterior cruciate ligament injury in high school and college female athletes: A Prospective Study. Am J Sports Med. 2019. https://doi.org/10.1177/0363546519886260.

54. Goshima K, Kitaoka K, Nakase J, Tsuchiya H. Familial predisposition to anterior cruciate ligament injury. Asia Pac J Sports Med Arthrosc Rehabil Technol. 2014;1(2):62-6.

55. Heath EL, Salmon LJ, Cooper R, Pappas E, Roe JP, Pinczewski LA. 5-Year survival of pediatric anterior cruciate ligament reconstruction with living donor hamstring tendon grafts. Am J Sports Med. 2019;47(1):41-51.

56. Kaeding CC, Pedroza AD, Reinke EK, Huston LJ, Spindler KP. Risk factors and predictors of subsequent ACL injury in either knee after ACL reconstruction: prospective analysis of 2488 
primary acl reconstructions from the MOON cohort. Am J Sports Med. 2015;43(7):1583-90.

57. Lai CCH, Feller JA, Webster KE. Fifteen-year audit of anterior cruciate ligament reconstructions in the australian football league from 1999 to 2013: return to play and subsequent ACL injury. Am J Sports Med. 2018;46(14):3353-60.

58. Larson CM, Bedi A, Dietrich ME, Swaringen JC, Wulf CA, Rowley DM, et al. Generalized hypermobility, knee hyperextension, and outcomes after anterior cruciate ligament reconstruction: prospective, case-control study with mean 6 years follow-up. Arthroscopy. 2017;33(10):1852-8.

59. Levins JG, Argentieri EC, Sturnick DR, Gardner-Morse M, Vacek PM, Tourville TW, et al. Geometric characteristics of the knee are associated with a noncontact ACL injury to the contralateral knee after unilateral ACL injury in young female athletes. Am J Sports Med. 2017;45(14):3223-32.

60. Leys T, Salmon L, Waller A, Linklater J, Pinczewski L. Clinical results and risk factors for reinjury 15 years after anterior cruciate ligament reconstruction: a prospective study of hamstring and patellar tendon grafts. Am J Sports Med. 2012;40(3):595-605.

61. Magnussen RA, Reinke EK, Huston LJ, Hewett TE, Spindler KP, Amendola A, et al. Effect of high-grade preoperative knee laxity on 6-year anterior cruciate ligament reconstruction outcomes. Am J Sports Med. 2018;46(12):2865-72.

62. Maletis GB, Inacio MC, Funahashi TT. Risk factors associated with revision and contralateral anterior cruciate ligament reconstructions in the Kaiser Permanente ACLR registry. Am J Sports Med. 2015;43(3):641-7.

63. Mardani-Kivi M, Mobarakeh MK, Keyhani S, Ebrahim-Zadeh $\mathrm{MH}$, Azari Z. Contralateral and siblings' knees are at higher risk of ACL tear for patients with a positive history of ACL tear. Knee Surg Sports Traumatol Arthrosc. 2020;28(2):622-8.

64. Mohtadi N, Chan D, Barber R, Paolucci EO. Reruptures, reinjuries, and revisions at a minimum 2-year follow-up: a randomized clinical trial comparing 3 graft types for ACL reconstruction. Clin J Sport Med. 2016;26(2):96-107.

65. Morgan MD, Salmon LJ, Waller A, Roe JP, Pinczewski LA. Fifteen-year survival of endoscopic anterior cruciate ligament reconstruction in patients aged 18 years and younger. Am J Sports Med. 2016;44(2):384-92.

66. Nakase J, Tsuchiya H, Kitaoka K. Contralateral anterior cruciate ligament injury after anterior cruciate ligament reconstruction: a case controlled study. Sports Med Arthrosc Rehabil Ther Technol. 2012;4(1):46.

67. Patel NM, Talathi NS, Bram JT, DeFrancesco CJ, Ganley TJ. How does obesity impact pediatric anterior cruciate ligament reconstruction? Arthroscopy. 2019;35(1):130-5.

68. Paterno MV, Flynn K, Thomas S, Schmitt LC. Self-reported fear predicts functional performance and second acl injury after ACL reconstruction and return to sport: a pilot study. Sports Health. 2018;10(3):228-33.

69. Perkins CA, Busch MT, Christino M, Herzog MM, Willimon SC. Allograft augmentation of hamstring anterior cruciate ligament autografts is associated with increased graft failure in children and adolescents. Am J Sports Med. 2019;47(7):1576-82.

70. Pfeiffer TR, Burnham JM, Hughes JD, Kanakamedala AC, Herbst E, Popchak A, et al. An increased lateral femoral condyle ratio is a risk factor for anterior cruciate ligament injury. J Bone Jt Surg Am. 2018;100(10):857-64.

71. Pinczewski LA, Lyman J, Salmon LJ, Russell VJ, Roe J, Linklater J. A 10-year comparison of anterior cruciate ligament reconstructions with hamstring tendon and patellar tendon autograft: a controlled, prospective trial. Am J Sports Med. 2007;35(4):564-74.
72. Pujol N, Blanchi MP, Chambat P. The incidence of anterior cruciate ligament injuries among competitive Alpine skiers: a 25-year investigation. Am J Sports Med. 2007;35(7):1070-4.

73. Rosenstiel N, Praz C, Ouanezar H, Saithna A, Fournier Y, Hager $\mathrm{JP}$, et al. Combined anterior cruciate and anterolateral ligament reconstruction in the professional athlete: clinical outcomes From the Scientific Anterior Cruciate Ligament Network International Study Group in a series of 70 patients with a minimum follow-up of 2 years. Arthroscopy. 2019;35(3):885-92.

74. Salmon L, Russell V, Musgrove T, Pinczewski L, Refshauge K. Incidence and risk factors for graft rupture and contralateral rupture after anterior cruciate ligament reconstruction. Arthroscopy. 2005;21(8):948-57.

75. Salmon LJ, Heath E, Akrawi H, Roe JP, Linklater J, Pinczewski LA. 20-Year outcomes of anterior cruciate ligament reconstruction with hamstring tendon autograft: the catastrophic effect of age and posterior tibial slope. Am J Sports Med. 2018;46(3):531-43.

76. Salmon LJ, Russell VJ, Refshauge K, Kader D, Connolly C, Linklater J, et al. Long-term outcome of endoscopic anterior cruciate ligament reconstruction with patellar tendon autograft: minimum 13-year review. Am J Sports Med. 2006;34(5):721-32.

77. Schickendantz MS, Weiker GG. The predictive value of radiographs in the evaluation of unilateral and bilateral anterior cruciate ligament injuries. Am J Sports Med. 1993;21(1):110-3.

78. Schmale GA, Kweon C, Larson RV, Bompadre V. High satisfaction yet decreased activity 4 years after transphyseal ACL reconstruction. Clin Orthop Relat Res. 2014;472(7):2168-74.

79. Shelbourne KD, Davis TJ, Klootwyk TE. The relationship between intercondylar notch width of the femur and the incidence of anterior cruciate ligament tears. A prospective study. Am J Sports Med. 1998;26(3):402-8.

80. Shelbourne KD, Gray T, Haro M. Incidence of subsequent injury to either knee within 5 years after anterior cruciate ligament reconstruction with patellar tendon autograft. Am J Sports Med. 2009;37(2):246-51.

81. Souryal TO, Moore HA, Evans JP. Bilaterality in anterior cruciate ligament injuries: associated intercondylar notch stenosis. Am J Sports Med. 1988;16(5):449-54.

82. Sousa PL, Krych AJ, Cates RA, Levy BA, Stuart MJ, Dahm DL. Return to sport: does excellent 6-month strength and function following ACL reconstruction predict midterm outcomes? Knee Surg Sports Traumatol Arthrosc. 2017;25(5):1356-63.

83. Wasserstein D, Khoshbin A, Dwyer T, Chahal J, Gandhi R, Mahomed N, et al. Risk factors for recurrent anterior cruciate ligament reconstruction: a population study in Ontario, Canada, with 5-year follow-up. Am J Sports Med. 2013;41(9):2099-107.

84. Wright RW, Dunn WR, Amendola A, Andrish JT, Bergfeld J, Kaeding CC, et al. Risk of tearing the intact anterior cruciate ligament in the contralateral knee and rupturing the anterior cruciate ligament graft during the first 2 years after anterior cruciate ligament reconstruction: a prospective MOON cohort study. Am J Sports Med. 2007;35(7):1131-4.

85. Webb JM, Salmon LJ, Leclerc E, Pinczewski LA, Roe JP. Posterior tibial slope and further anterior cruciate ligament injuries in the anterior cruciate ligament-reconstructed patient. Am J Sports Med. 2013;41(12):2800-4.

86. Higgins JP, Thompson SG, Deeks JJ, Altman DG. Measuring inconsistency in meta-analyses. BMJ. 2003;327(7414):557-60.

87. Deitch JR, Starkey C, Walters SL, Moseley JB. Injury risk in professional basketball players: a comparison of Women's National Basketball Association and National Basketball Association athletes. Am J Sports Med. 2006;34(7):1077-83.

88. Stanley LE, Kerr ZY, Dompier TP, Padua DA. Sex differences in the incidence of anterior cruciate ligament, medial collateral ligament, and meniscal injuries in collegiate and high school 
sports: 2009-2010 through 2013-2014. Am J Sports Med. 2016;44(6):1565-72.

89. Montalvo AM, Schneider DK, Yut L, Webster KE, Beynnon B, Kocher MS, et al. "What's my risk of sustaining an ACL injury while playing sports?" a systematic review with meta-analysis. Br J Sports Med. 2019;53(16):1003-12.

90. Prodromos CC, Han Y, Rogowski J, Joyce B, Shi K. A metaanalysis of the incidence of anterior cruciate ligament tears as a function of gender, sport, and a knee injury-reduction regimen. Arthroscopy. 2007;23(12):1320-5 e6.

91. Herzberg SD, Motu'apuaka ML, Lambert W, Fu R, Brady J, Guise JM. The effect of menstrual cycle and contraceptives on ACL injuries and laxity: a systematic review and meta-analysis. Orthop J Sports Med. 2017;5(7):2325967117718781.

92. Weiss K, Whatman C. Biomechanics associated with patellofemoral pain and acl injuries in sports. Sports Med. 2015;45(9):1325-37.

93. Cronstrom A, Ageberg E, Franettovich Smith MM, Blackmore T, Nae J, Creaby MW. Factors affecting knee abduction during weight-bearing activities in individuals with anterior cruciate ligament reconstruction. Phys Ther Sport. 2019;38:8-15.

94. Shultz SJ, Nguyen AD, Schmitz RJ. Differences in lower extremity anatomical and postural characteristics in males and females between maturation groups. J Orthop Sports Phys Ther. 2008;38(3):137-49.

95. Quatman-Yates CC, Quatman CE, Meszaros AJ, Paterno MV, Hewett TE. A systematic review of sensorimotor function during adolescence: a developmental stage of increased motor awkwardness? Br J Sports Med. 2012;46(9):649-55.

96. John R, Dhillon MS, Sharma S, Prabhakar S, Bhandari M. Is there a genetic predisposition to anterior cruciate ligament tear? A systematic review. Am J Sports Med. 2016;44(12):3262-9.

97. Sivertsen EA, Haug KBF, Kristianslund EK, Troseid AS, Parkkari J, Lehtimaki T, et al. No association between risk of anterior cruciate ligament rupture and selected candidate collagen gene variants in female elite athletes from high-risk team sports. Am J Sports Med. 2019;47(1):52-8.

98. Kaynak M, Nijman F, van Meurs J, Reijman M, Meuffels DE. Genetic variants and anterior cruciate ligament rupture: a systematic review. Sports Med. 2017;47(8):1637-50.

99. Seale K, Burger M, Posthumus M, Häger CK, Stattin E, Nilsson KG, Collins M, September AV. The apoptosis pathway and CASP8 variants conferring risk for acute and overuse musculoskeletal injuries. J Orthop Res. 2020;38(3):680-8.

100. Suijkerbuijk MAM, Ponzetti M, Rahim M, Posthumus M, Hager CK, Stattin E, et al. Functional polymorphisms within the inflammatory pathway regulate expression of extracellular matrix components in a genetic risk dependent model for anterior cruciate ligament injuries. J Sci Med Sport. 2019;22(11):1219-25.

101. Li H, Zeng C, Wang Y, Wei J, Yang T, Cui Y, et al. Association between magnetic resonance imaging-measured intercondylar notch dimensions and anterior cruciate ligament injury: a metaanalysis. Arthroscopy. 2018;34(3):889-900.

102. Bowers AL, Spindler KP, McCarty EC, Arrigain S. Height, weight, and BMI predict intra-articular injuries observed during ACL reconstruction: evaluation of 456 cases from a prospective ACL database. Clin J Sport Med. 2005;15(1):9-13.
103. Brambilla L, Pulici L, Carimati G, Quaglia A, Prospero E, Bait $\mathrm{C}$, et al. Prevalence of associated lesions in anterior cruciate ligament reconstruction: correlation with surgical timing and with patient age, sex, and body mass index. Am J Sports Med. 2015;43(12):2966-73.

104. Magnussen RA, Borchers JR, Pedroza AD, Huston LJ, Haas AK, Spindler KP, et al. Risk factors and predictors of significant chondral surface change from primary to revision anterior cruciate ligament reconstruction: a MOON and MARS Cohort Study. Am J Sports Med. 2018;46(3):557-64.

105. Anderson MJ, Browning WM 3rd, Urband CE, Kluczynski MA, Bisson LJ. A systematic summary of systematic reviews on the topic of the anterior cruciate ligament. Orthop J Sports Med. 2016;4(3):2325967116634074.

106. Grindem H, Snyder-Mackler L, Moksnes H, Engebretsen L, Risberg MA. Simple decision rules can reduce reinjury risk by $84 \%$ after ACL reconstruction: the Delaware-Oslo ACL cohort study. Br J Sports Med. 2016;50(13):804-8.

107. King E, Richter C, Jackson M, Franklyn-Miller A, Falvey E, Myer GD, et al. Factors influencing return to play and second anterior cruciate ligament injury rates in level 1 athletes after primary anterior cruciate ligament reconstruction: 2-year followup on 1432 Reconstructions at a Single Center. Am J Sports Med. 2020;48(4):812-24.

108. Beischer S, Gustavsson L, Senorski EH, Karlsson J, Thomeé C, Samuelsson K, et al. Young athletes who return to sport before 9 months after anterior cruciate ligament reconstruction have a rate of new injury 7 times that of those who delay return. J Orthop Sports Phys Ther. 2020;50(2):83-90.

109. Losciale JM, Zdeb RM, Ledbetter L, Reiman MP, Sell TC. The association between passing return-to-sport criteria and second anterior cruciate ligament injury risk: a systematic review with meta-analysis. J Orthop Sports Phys Ther. 2019;49(2):43-54.

110. Webster KE, Hewett TE. What is the evidence for and validity of return-to-sport testing after anterior cruciate ligament reconstruction surgery? A systematic review and meta-analysis. Sports Med. 2019;49(6):917-29.

111. Snaebjornsson T, Svantesson E, Sundemo D, Westin O, Sansone $\mathrm{M}$, Engebretsen L, et al. Young age and high BMI are predictors of early revision surgery after primary anterior cruciate ligament reconstruction: a cohort study from the Swedish and Norwegian knee ligament registries based on 30,747 patients. Knee Surg Sports Traumatol Arthrosc. 2019;27(11):3583-91.

112. Novikov DA, Swensen SJ, Buza JA 3rd, Gidumal RH, Strauss EJ. The effect of smoking on ACL reconstruction: a systematic review. Phys Sportsmed. 2016;44(4):335-41.

113. Capin JJ, Khandha A, Zarzycki R, Manal K, Buchanan TS, Snyder-Mackler L. Gait mechanics and second ACL rupture: implications for delaying return-to-sport. J Orthop Res. 2017;35(9):1894-901.

114. Thorlund K, Imberger G, Walsh M, Chu R, Gluud C, Wetterslev $\mathrm{J}$, et al. The number of patients and events required to limit the risk of overestimation of intervention effects in meta-analysis-a simulation study. PLoS ONE. 2011;6(10):e25491.

115. Thompson SG, Higgins JP. How should meta-regression analyses be undertaken and interpreted? Stat Med. 2002;21(11):1559-73. 